no.

c. 3

Army Corps

ngineers

rways Experiment

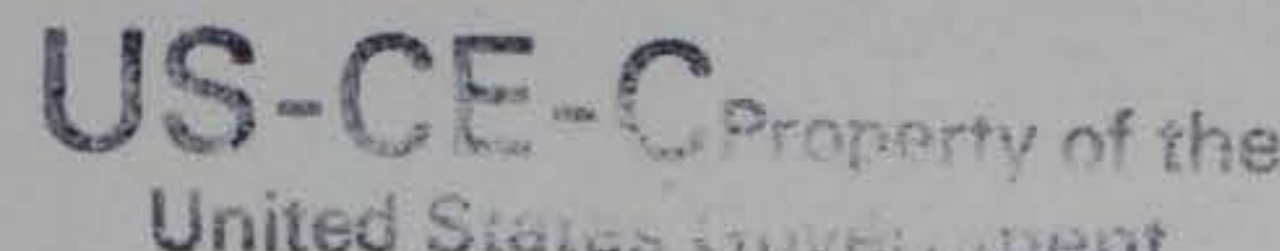

United Statco wuvei...nent

गn

Water Quality Research Program

\title{
Description of Contaminant Sediment-Water Interactions Using RECOVERY
}

by Thomas C. Sturgis, Carlos Ruiz, Douglas Gunnison, Judith C. Pennington Environmental Laboratory

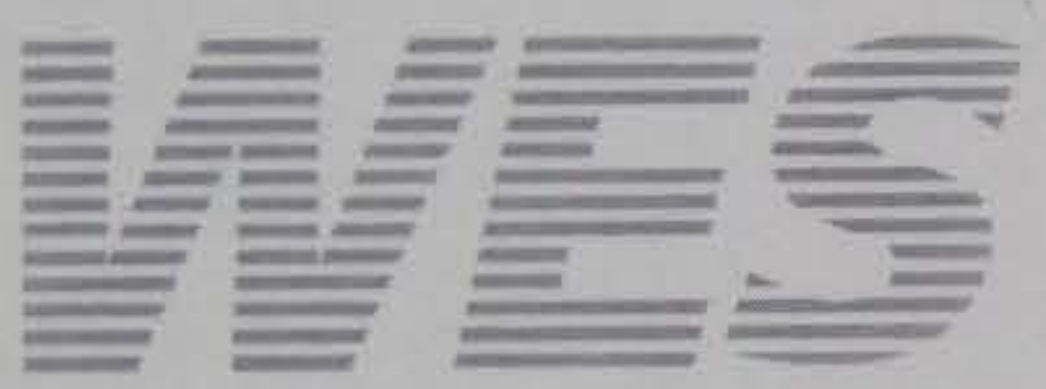

Approved For Public Release; Distribution Is Unlimited

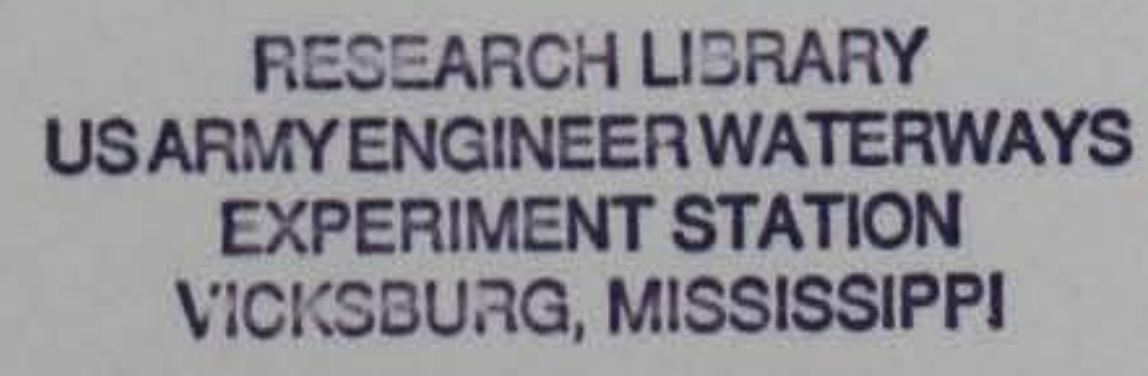


TA 7

W34

no. $\omega-93-1$

c. 3

Technical Report W-93-1

April 1993

\section{Description of Contaminant Sediment-Water Interactions Using RECOVERY}

by Thomas C. Sturgis, Carlos Ruiz, Douglas Gunnison, Judith C. Pennington

Environmental Laboratory

U.S. Army Corps of Engineers Waterways Experiment Station 3909 Halls Ferry Road

Vicksburg, MS 39180-6199

Final report

Approved for public release; distribution is unlimited

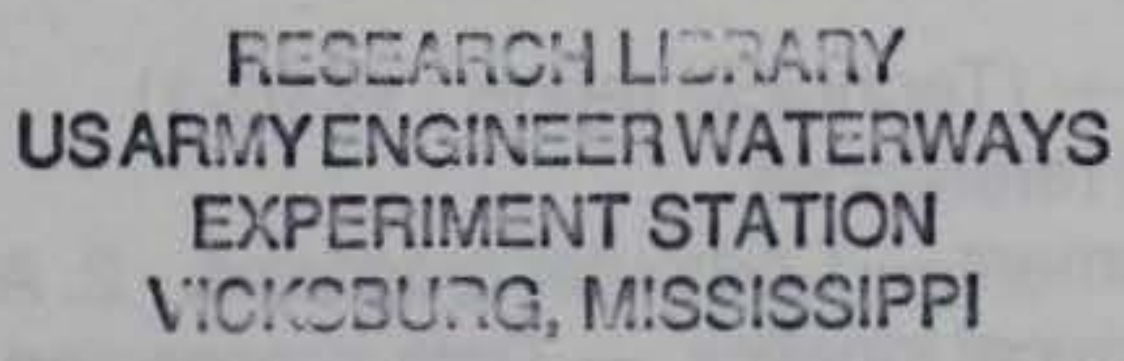

Prepared for U.S. Army Corps of Engineers

Washington, DC 20314-1000 


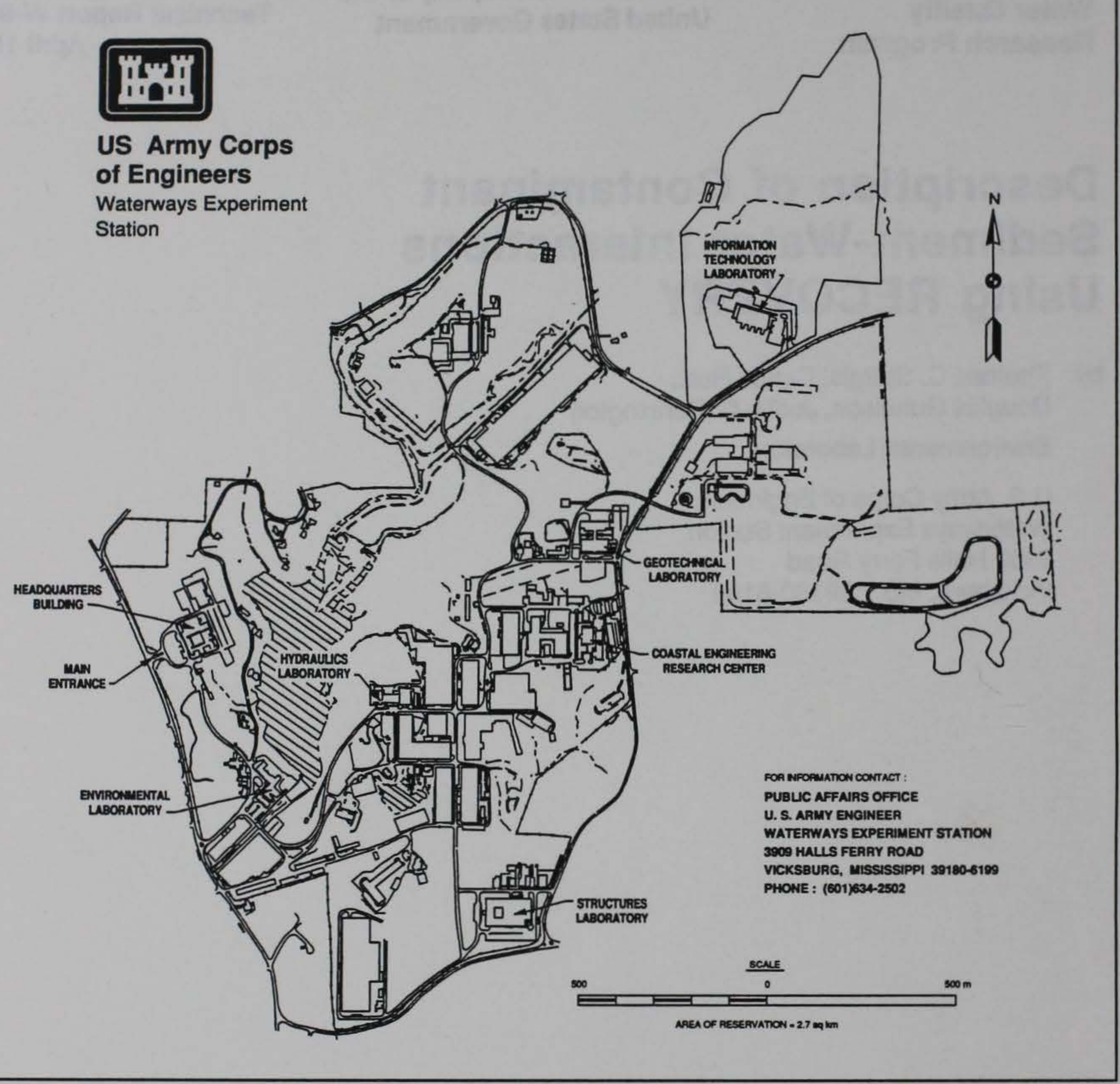

\section{Waterways Experiment Station Cataloging-in-Publication Data}

Description of contaminant sediment-water interactions using RECOVERY / by Thomas C. Sturgis ... [et al.] ; prepared for U.S. Army Corps of Engineers.

28, [30] p. : ill. ; $28 \mathrm{~cm}$. - (Technical report ; W-93-1)

Includes bibliographical references.

1. Water quality management - Computer programs. 2. Adsorption Data processing. 3. Chemical kinetics - Data processing. 4. Organic water pollutants. I. Sturgis, Thomas C. II. United States. Army. Corps of Engineers. III. U.S. Army Engineer Waterways Experiment Station. IV. Water Quality Research Program. V. Series: Technical report (U.S. Army Engineer Waterways Experiment Station) ; W-93-1. 
The work reported herein was conducted as part of the Water Quality Research Program (WQRP), Work Unit 32513, "Sediment-Water Interactions and Contaminant Processes in Reservoirs." The WQRP is sponsored by the Headquarters, US Army Corps of Engineers (HQUSACE), and is assigned to the US Army Engineer Waterways Experiment Station (WES) under the purview of the Environmental Laboratory (EL). Funding was provided under Department of the Army Appropriation No. 96×3121, General Investigation. The WQRP is managed under the Environmental Resources Research and Assistance Programs (ERRAP), Mr. J. L. Decel1, Manager. Mr. Robert C. Gunkel was Assistant Manager, ERRAP, for the WQRP. Technical Monitors during the study were Mr. Frederick B. Juhle, Mr. James Gottesman, and Dr. John Bushman, HQUSACE.

The study was conducted and the report prepared by Mr. Thomas C. Sturgis and Drs. Douglas Gunnison and Judith C. Pennington, Ecosystem Processes and Effects Branch (EPEB), and Dr. Carlos Ruiz, Water Quality and Contaminant Modeling Branch, Environmental Processes and Effects Division (EPED), EL.

The study was conducted under the direct supervision of Dr. Richard E. Price, Chief, EPEB, and under the general supervision of Mr. Donald L. Robey, Chief, EPED, and Dr. John Harrison, Director, EL. Technical reviews of the report were provided by Dr. James M. Brannon and Mr. Dennis Brandon, EPED.

At the time of publication of this report, Director of WES was Dr. Robert W. Whalin. Commander was COL Leonard G. Hasse11, EN.

This report should be cited as follows:

Sturgis, Thomas C., Ruiz, Carlos, Gunnison, Douglas, and Pennington, Judith C. 1993. "Description of Contaminant Sediment-Water Interactions using RECOVERY," Technical Report W-93-1, US Army Engineer Waterways Experiment Station, Vicksburg, MS. 


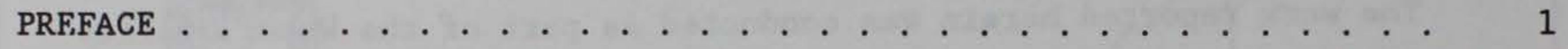

LIST $\mathrm{OF}$ TABLES . . . . . . . . . . . . . . . . . . . . . . . . . . . . 3

LIST OF FIGURES . . . . . . . . . . . . . . . . . . . . . . . . . . . . . . . 3

CONVERSION FACTORS, NON-SI TO SI UNITS OF MEASUREMENT . . . . . . . . . 4

PART I: INTRODUCTION . . . . . . . . . . . . . . . . . 5

PART II: MATERIALS AND METHODS . . . . . . . . . . . . . . 7

Organic Chemicals . . . . . . . . . . . . . . . . . . . . . . 7

Sediments . . . . . . . . . . . . . . . . . . 8

Batch Studies . . . . . . . . . . . . . . . . . 8

Model Description . . . . . . . . . . . . . . . . 10

PART III: RESULTS . . . . . . . . . . . . . . . . . . . . . . . . . . . 11

Sediment Physical Characteristics . . . . . . . . . . . 11

Desorption Kinetics Study . . . . . . . . . . . . . . . . . . . . 11

Model Application . . . . . . . . . . . . . . . . . . . . . . . 15

PART IV: DISCUSSION . . . . . . . . . . . . . . . . . . . . . . . 22

Desorption Kinetics . . . . . . . . . . . . . . . . . . . . 22

RECOVERY Model ...................... . . . . 23

PART V: SUMMARY AND CONCLUSIONS . . . . . . . . . . . . . . . 25

REFERENCES . . . . . . . . . . . . . . . . . . . . . . 26

APPENDIX A: RECOVERY MODEL DESCRIPTION, USER'S GUIDE, AND

INSTALLATION AND RUN . . . . . . . . . . . . . . . . . . A1 


\section{LIST OF TABLES}

No.

Page

1 Physical Characteristics of Sediments . . . . . . . . . . . . . . 8

$2 \mathrm{~K}_{\mathrm{oc}}$ Values for Each Contaminant . . . . . . . . . . . . . . . . . 11

3 Desorption Partition Coefficients $\left(\mathrm{K}_{\mathrm{d}}\right)$ for Each Contaminant . . . 12

4 Percentage of Contaminant Desorbed from Each Sediment . . . . . . 15

\section{LIST OF FIGURES}

No.

1 Molecular structures for fluoranthene, naphthalene, and polychlorinated biphenyl and location of $\left[{ }^{14} \mathrm{C}\right]$. . . . . . . . 7

2 Kinetic curves for desorption of fluoranthene . . . . . . . . . . 13

3 Kinetic curves for desorption of naphthalene . . . . . . . . . . . 14

4 Kinetic curves for desorption of PCB 153 . . . . . . . . . . . . . . . 16

5 Experimental and predicted kinetic curves for desorption of fluoranthene ..................... . 17

6 Experimental and predicted kinetic curves for desorption of naphthalene ........................... 18

$7 \quad$ Kinetic curves for naphthalene desorption from Wayne County . . . 19

8 Experimental and predicted kinetics curves for desorption of PCB 153 ..................... . . 21 


\section{CONVERSION FACTORS, NON-SI TO SI \\ UNITS OF MEASUREMENT}

Non-SI units of measurement used in this report can be converted to SI units
$\begin{array}{lcc}\text { as follows: } & & \text { By } \\ \text { Multiply } & 4,046.873 & \text { Tobtain } \\ \text { acres } & 0.3048 & \text { meters } \\ \text { feet } & 1.609347 & \text { kilometers } \\ \text { miles (US statute) } & 907.1847 & \text { kilograms } \\ \text { tons (2,000 pounds, mass) } & \end{array}$




\section{DESCRIPTION OF CONTAMINANT SEDIMENT-WATER \\ INTERACTIONS USING RECOVERY}

\section{PART I: INTRODUCTION}

1. Bedded sediments serve as sinks for many contaminants. Deposition of contaminants into the sediment begins a series of processes that may cycle contaminants back into the water column creating potentially adverse ecological impacts on aquatic biota. Sorption processes influence the mobility of contaminants from the sediment. Sorption is a general term referring to chemical binding that may be both reversible and irreversible. Desorption quantifies the reversibility of contaminants and is important because the availability of contaminants for uptake depends on the rate of desorption. The partitioning of contaminants between sediment and aqueous phases influences sorption processes and can be mathematically written as:

$$
\mathrm{K}_{\mathrm{d}}=\mathrm{C}_{\mathrm{s}} / \mathrm{C}_{\mathrm{w}}
$$

where

$$
\begin{aligned}
& \mathrm{K}_{\mathrm{d}}=\text { the distribution coefficient, } \ell / \mathrm{kg} \\
& \mathrm{C}_{\mathrm{s}}=\text { the concentration of contaminant sorbed to sediment solids, mg/kg } \\
& \mathrm{C}_{\mathrm{w}}=\text { the concentration of contaminant in aqueous phase, mg/ } \ell
\end{aligned}
$$

Because the distribution coefficient of nonpolar organic compounds such as polycyclic aromatic hydrocarbons (PAHs) is strongly dependent on sediment organic-matter content, the distribution coefficient is usually normalized for organic content of the sediment:

$$
\mathrm{K}_{\mathrm{oc}}=\mathrm{K}_{\mathrm{d}} / \mathrm{f}_{\mathrm{oc}}
$$

where

$$
\begin{aligned}
& K_{o c}=\text { the normalized partition coefficient } \\
& f_{o c}=\text { the fraction of organic carbon in the sediment }
\end{aligned}
$$
Partitioning and sorption are key processes that must be understood to determine the role and potential impacts of the sediment in contaminant mobilization on the aquatic biota. 
2. The overall objective of this study was to use experimental data and a model simulation to predict desorption kinetics of organic contaminants and to assess the potential effect of contaminated sediment on the overlying water. In the experimental phase, several PAHs and polychlorinated biphenyl (PCB) 153 were quantified. Radiolabeled PAHs and PCB 153 were selected as tracers to determine the rate and magnitude of contaminant mobilization from five reservoir sediments. Data from the experimental phase will be used to verify and assess the applicability of the RECOVERY model in predicting desorption.

3. Concern about environmental exposure to contaminants has increased the need to predict the fate of anthropogenic organic contaminants entering aquatic systems. A primary sink for contaminants is the sediment. The RECOVERY model permits estimation of desorption rates and allows assessment of the potential adverse impact of contaminated sediments on the overlying water and biota. The model assumes that the contaminants follow linear equilibrium sorption and first-order decay kinetics. Partitioning models in which equilibrium between sorbed and dissolved species is assumed are often sufficient to describe the transport fate of contaminants, particularly when incubation periods are relatively long (days to months) (Neeley and Blau 1977; Watanbe 1985). Once desorption rates are predicted, a hazard assessment can be made on a given reservoir project. 


\section{PART II: MATERIALS AND METHODS}

\section{Organic Chemicals}

4. To demonstrate the impact of sediment-water interactions on contaminant levels in US Army Corps of Engineer (USACE) reservoir projects, radiolabeled contaminants such as $2,2^{\prime}, 4,4^{\prime}, 5,5^{\prime}$-Hexachlorobiphenyl-UL- ${ }^{14} \mathrm{C}$ (PCB 153), $\left[3-{ }^{14} \mathrm{C}\right]$ fluoranthene and naphthalene $-1-{ }^{14} \mathrm{C}$ were used as model chemicals (Figure 1). Information obtained using these chemicals can provide insight into the impact of other PCBs (e.g., pentachlorobiphenyl) and PAHs (e.g., fluorene, anthracene, and phenanthrene). Fluoranthene and naphthalene represent a wide range of solubilities and $\log$ octanol/water coefficients. Fluoranthene is a three-ring aromatic hydrocarbon that is sparingly soluble in

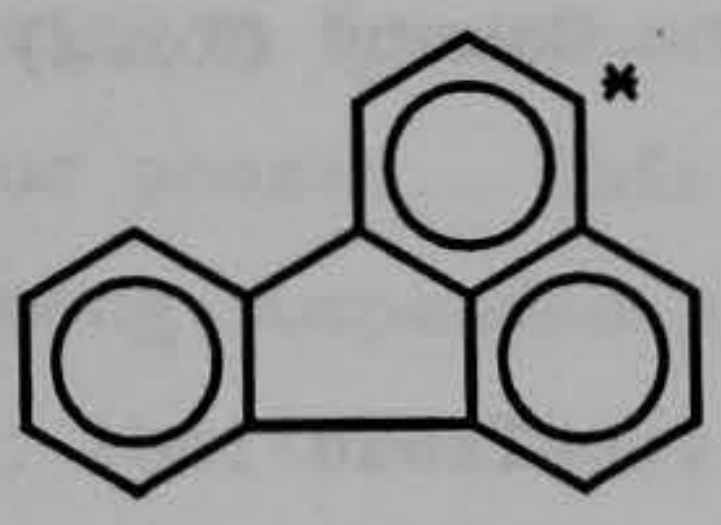

a. Fluoranthene<smiles>c1ccc2ccccc2c1</smiles>

b. Naphthalene

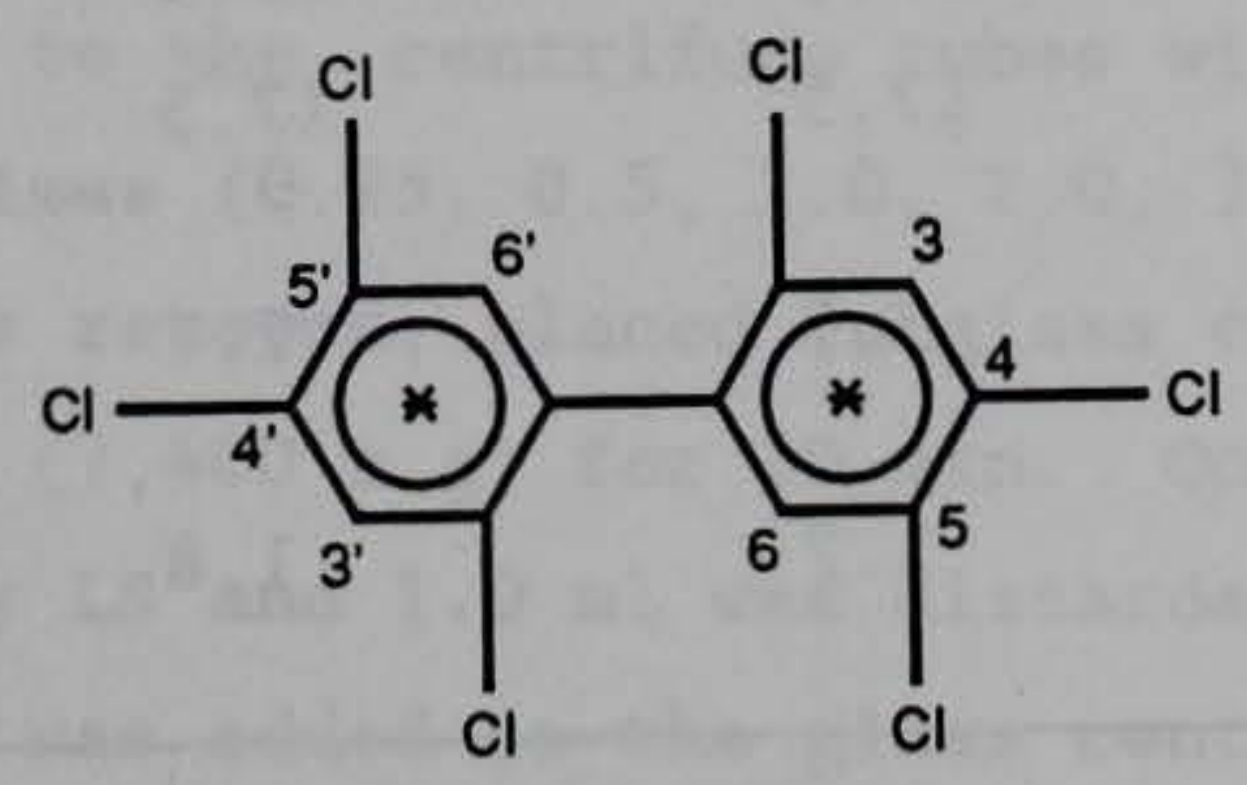

c. Polychlorinated biphenyl

Figure 1. Molecular structures for fluoranthene, naphthalene, and polychlorinated biphenyl and location of $\left[{ }^{14} \mathrm{C}\right]$ 
water $(0.26 \mathrm{mg} / \ell)$. Naphthalene is a two-ring aromatic hydrocarbon having an aqueous solubility of $34 \mathrm{mg} / \ell$. Fluoranthene and naphthalene have $10 \mathrm{~g}$ octanol/water coefficients of 5.33 and 3.37 , respectively (Radding et al. 1976; Leo and Elkins 1971).

5. $Р C B$ is the generic name for a group of related compounds (congeners) having 209 possible individual configurations (McFarland, Clarke, and Gibson 1986). The congeners differ in number and position of chlorine atoms substituted for hydrogen on the biphenyl molecule. PCB 153 has a low water solubility $(0.04$ to $0.2 \mathrm{mg} / \ell)$ and a $\log$ octanol/water coefficient of 6.03 .

\section{Sediments}

6. Five sediments with organic carbon ranging from 1.2 to 9 percent were selected. They were Mark Twain Lake (Missouri), Louisville (Kentucky), Brown's Lake (Mississippi), Wayne County (Iowa), and Oakland Inner Harbor (California) (Table 1).

Table 1

Physical Characteristics of Sediments

\begin{tabular}{|c|c|c|c|c|c|}
\hline \multirow[b]{2}{*}{ Constituent } & \multicolumn{5}{|c|}{ Concentration of Constituent, percent } \\
\hline & $\begin{array}{l}\text { Louisville } \\
\text { Lake Sediment }\end{array}$ & $\begin{array}{l}\text { Mark Twain } \\
\text { Lake Sediment }\end{array}$ & $\begin{array}{l}\text { Oakland } \\
\text { Inner } \\
\text { Harbor } \\
\text { Sediment }\end{array}$ & $\begin{array}{l}\text { Brown's Lake } \\
\text { Sediment }\end{array}$ & $\begin{array}{c}\text { Wayne } \\
\text { County } \\
\text { Sediment }\end{array}$ \\
\hline Sand & 10.0 & 45.0 & 72.5 & 5.0 & 57.5 \\
\hline Silt & 75.0 & 37.5 & 10.0 & 70.0 & 27.5 \\
\hline Clay & 15.0 & 17.5 & 17.5 & 25.0 & 15.0 \\
\hline $\begin{array}{l}\text { Organic } \\
\text { Matter }\end{array}$ & 5.7 & 3.7 & 2.7 & 3.1 & 5.5 \\
\hline $\begin{array}{l}\text { Organic } \\
\text { Carbon }\end{array}$ & 2.6 & 1.2 & 1.8 & 2.8 & 9.0 \\
\hline
\end{tabular}

\section{Batch Studies}

7. Batch studies to assess the release of organic contaminants from sediment were determined in 25-ml glass centrifuge tubes. These experiments were conducted in the laboratory where the temperature was maintained at 
$20{ }^{\circ} \mathrm{C} \pm 0.5^{\circ} \mathrm{C}$. Each sediment was spiked with $1 \mathrm{ppm} 2,2^{\prime}, 4,4^{\prime}, 5^{\prime}$ - Hexachlorobiphenyl-UL- ${ }^{14} \mathrm{C}$ (PCB 153), $\left[3-{ }^{14} \mathrm{C}\right]$ fluoranthene, and naphthalene $-1-{ }^{14} \mathrm{C}$. The specific activities of РСB 153, fluoranthene, and naphthalene are 12.2, 55.0, and $10.1 \mathrm{mCi} / \mathrm{mmol}$, respectively; chemical and radiological purities were greater than 98 percent by high performance liquid chromatography and radio thin layer chromatography, respectively. Sediments were spiked with PCB 153 and fluoranthene by coating the side walls of glass centrifuge tubes with toluene and benzene solution of the contaminants, respectively. Tubes were allowed to turn on their sides on an electrical roller drum until the solvents evaporated. A sediment slurry with a 2:1 water to sediment ratio was then added to the glass centrifuge tubes. Naphthalene was added directly to the sediment slurry.

8. All glass centrifuge tubes were placed on a reciprocating box shaker and allowed to shake for $24 \mathrm{hr}$ at a speed of 280 excursions/min. This allowed the contaminants to partition from the walls of the glass centrifuge tubes to the sediment and aqueous phases. This technique produced a more uniform chemical distribution among suspended sediment particles (Karickhoff and Morris 1985). After $24 \mathrm{hr}$, the tubes were removed from the shaker. The upper inside walls of all tubes were cleaned, capped with foam plugs, and the contents allowed to settle for 3 days.

9. After 3 days, the overlying water was removed and centrifuged at $12,000 \mathrm{rpm}(7,400 \times \mathrm{g})$ for $30 \mathrm{~min}$. One milliliter of the supernatant was counted in $20 \mathrm{ml}$ of Aquasol (Cole-Palmer, Chicago, IL) in a Packard TriCarb 2500 Liquid Scintillation (LS) analyzer. Each sample was counted for 5 min through two cycles and the disintegrations per minute averaged. Distilled deionized water was added to the centrifuge tubes without disturbing the sediment. At specified times $(0.25,0.5,1.0,2.0,3.0,5.0,7.0$ days $), 2 \mathrm{ml}$ of the overlying water was removed, placed in glass centrifuge tubes, and centrifuged at $12,000 \mathrm{rpm}(7,400 \mathrm{x} \mathrm{g})$ for $30 \mathrm{~min}$. One milliliter of the supernatant was counted by $\mathrm{LS}$ and $1.0 \mathrm{ml}$ was discarded. Two milliliters of distilled deionized water was added to the glass centrifuge tubes to replace the water that was removed.

10. Following the last sampling, foam plugs were extracted three times with $5-\mathrm{ml}$ aliquots of hexane. The extracts were combined and concentrated to $5 \mathrm{ml}$. One milliliter of the concentrate was counted, and the remainder was frozen. for possible gas chromatography analysis. Controls (unspiked 
sediments) were sampled concurrent with the various radiolabeled treatments using the same procedures.

\section{Model Description}

11. To make hazard assessments, the extent and magnitude of the influence of contaminated sediment on the overlying water column must be delineated. RECOVERY, a PC-based zero dimension model, was developed to assess the impact of contaminated sediment on the overlying water (Boyer and Chapra 1989). The model was modified to make it more applicable to laboratory microcosm settings and short-term scenarios ( 7 days), and to facilitate use by USACE field offices for assessing the potential impact of contaminated sediment on the overlying water. The analysis is limited to organic contaminants and to well-mixed surface waters.

12. RECOVERY is designed for interactive implementation via personal computer. The program allows the user to generate and analyze the expected course of events for contaminated sediments. The results are displayed as plots of contaminant concentration in the water versus time and flux of the contaminant from the sediment into the water versus time. The model will only predict desorption (DiToro and Horzempa 1982). A more detailed description of the model and a model user's guide are presented in Appendix A.

13. Means and standard errors were determined for each parameter within a treatment. To determine the statistical significance of difference between means, t-tests were conducted. 


\section{Sediment Physical Characteristics}

14. Louisville and Brown's Lake sediments have higher percentages of fine material than Mark Twain, Oakland Harbor, and Wayne County sediments (Table 1). Organic carbon content was higher in Wayne County, Brown's Lake, and Louisville sediments $(9.0,2.8$, and 2.6 percent, respectively), than in Oakland and Mark Twain (1.8 and 1.2 percent, respectively). Partition coefficients (Table 2 ) normalized for organic matter content $\left(\mathrm{K}_{\mathrm{oc}}\right)$ are useful to estimate $K_{d}$ for other sediments with other values of $f_{o c}$ (fraction organic carbon) (Hamaker and Thompson 1972).

Table 2

$\underline{\mathrm{K}}_{\mathrm{oc}}$ Values for Each Contaminant

\begin{tabular}{|c|c|c|c|}
\hline Sediment & Fluoranthene & Naphthalene & PCB 153 \\
\hline Mark Twain & $9.25 \times 10^{7}$ & $1.37 \times 10^{9}$ & $9.25 \times 10^{7}$ \\
\hline Louisville & $1.20 \times 10^{10}$ & $8.53 \times 10^{9}$ & $1.28 \times 10^{11}$ \\
\hline $\begin{array}{l}\text { Oakland Inner } \\
\text { Harbor }\end{array}$ & $1.10 \times 10^{10}$ & $1.88 \times 10^{9}$ & $1.25 \times 10^{11}$ \\
\hline Brown's Lake & $1.05 \times 10^{9}$ & $3.71 \times 10^{9}$ & $3.30 \times 10^{10}$ \\
\hline Wayne County & $1.46 \times 10^{9}$ & $9.25 \times 10^{8}$ & $7.40 \times 10^{9}$ \\
\hline
\end{tabular}

\section{Desorption Kinetics Study}

15. The desorption partition coefficients $\left(K_{d}\right)$ for each sediment are shown in Table 3 . $K_{d}$ was mathematically determined by dividing the concentration of the contaminant sorbed to sediment solids by the concentration of contaminant in the aqueous phase. The $K_{d}$ values provide estimates of organic contaminant desorption and indicate that desorption was minor.

Fluoranthene

16. Fluoranthene desorption was biphasic, consisting of a rapid phase, followed by a slower approach to steady state (Figure 2). Desorption from Louisville and Oakland sediments was essentially complete within the first 2 days. The decrease observed in fluoranthene concentration after 2 days was 
Table 3

\section{Desorption Partition Coefficients $\left(K_{d}\right)$ for Each Contaminant, $\ell / \mathrm{kg}$}

\begin{tabular}{lccc}
\hline \multicolumn{1}{c}{ Sediment } & Fluoranthene & Naphthalene & PCB 151 \\
Mark Twain & $1.11 \times 10^{7}$ & $1.64 \times 10^{6}$ & $1.11 \times 10^{7}$ \\
$\begin{array}{l}\text { Louisville } \\
\text { Oakland Inner }\end{array}$ & $3.13 \times 10^{7}$ & $2.22 \times 10^{7}$ & $3.33 \times 10^{8}$ \\
$\quad$ Harbor & $1.14 \times 10^{7}$ & $2.04 \times 10^{6}$ & $1.42 \times 10^{8}$ \\
Brown's Lake & $3.13 \times 10^{6}$ & $1.04 \times 10^{7}$ & $9.10 \times 10^{7}$ \\
Wayne County & $1.31 \times 10^{7}$ & $8.33 \times 10^{6}$ & $6.67 \times 10^{7}$ \\
\hline
\end{tabular}

not significant $(P<.01)$. Analysis of Mark Twain and Brown's Lake desorption kinetics show that desorption was complete after the first 2 days. Fluoranthene desorption from the Brown's Lake sediment showed an apparent increase throughout the study (Figure 2). However, between Days 3 and 7 , there was only a small increase of approximately $0.6 \mu \mathrm{g} / \ell$; this increase was not significant $(P<.01)$. Desorption from Wayne County sediment was essentially complete after the first day.

Naphthalene

17. Kinetic trends for naphthalene were similar among sediments (Figure 3), but the percentage of naphthalene desorption varied with sediment at steady state (Table 4). Wayne County and Brown's Lake sediments displayed similar trends and magnitude of desorption. Mark Twain and Oakland Inner Harbor sediments have the lowest sediment organic carbon content and the highest naphthalene desorption (approximately $11 \mu \mathrm{g} / \ell$ ). Generally, naphthalene was rapidly desorbed after $6 \mathrm{hr}$, followed by a gradual approach to steady state. The amount of naphthalene desorbed ranged from $<1$ percent (Louisville sediment) to 11 percent (Oakland sediment).

Polychlorinated biphenyl

18. Brown's Lake sediment achieved steady state after $2 \mathrm{hr}$ (Figure 4). The remaining sediments showed somewhat erratic desorption kinetics (Figure 4). Generally, <0.1 percent of the PCB 153 added to all sediments was desorbed with the exception of the Wayne County sediment (Table 4). Wayne County sediment, which has the highest total sediment organic carbon content, lost approximately 3.5 percent of its initial $\mathrm{PCB}$ content to desorption. This 

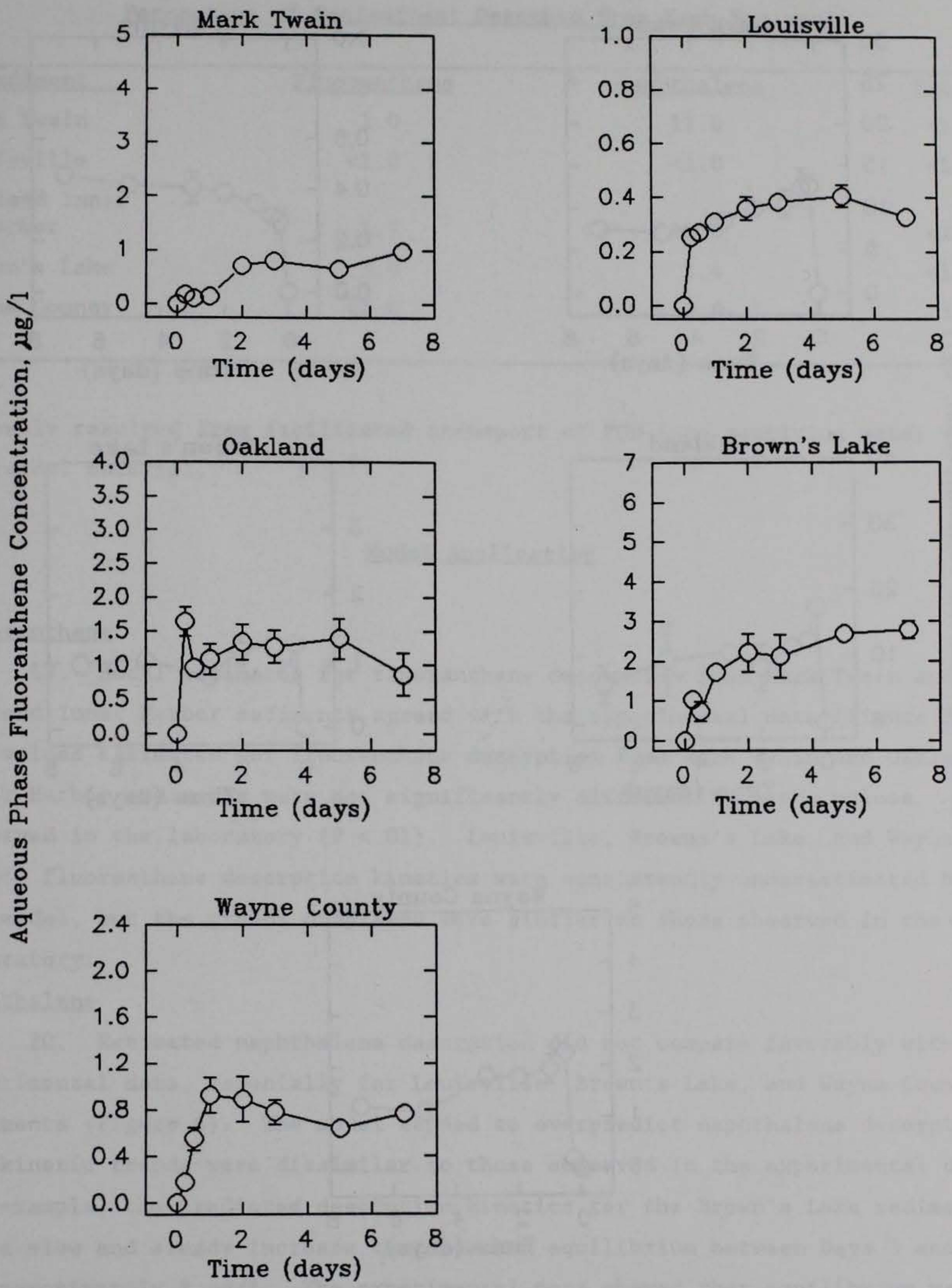

Figure 2. Kinetic curves for desorption of fluoranthene 

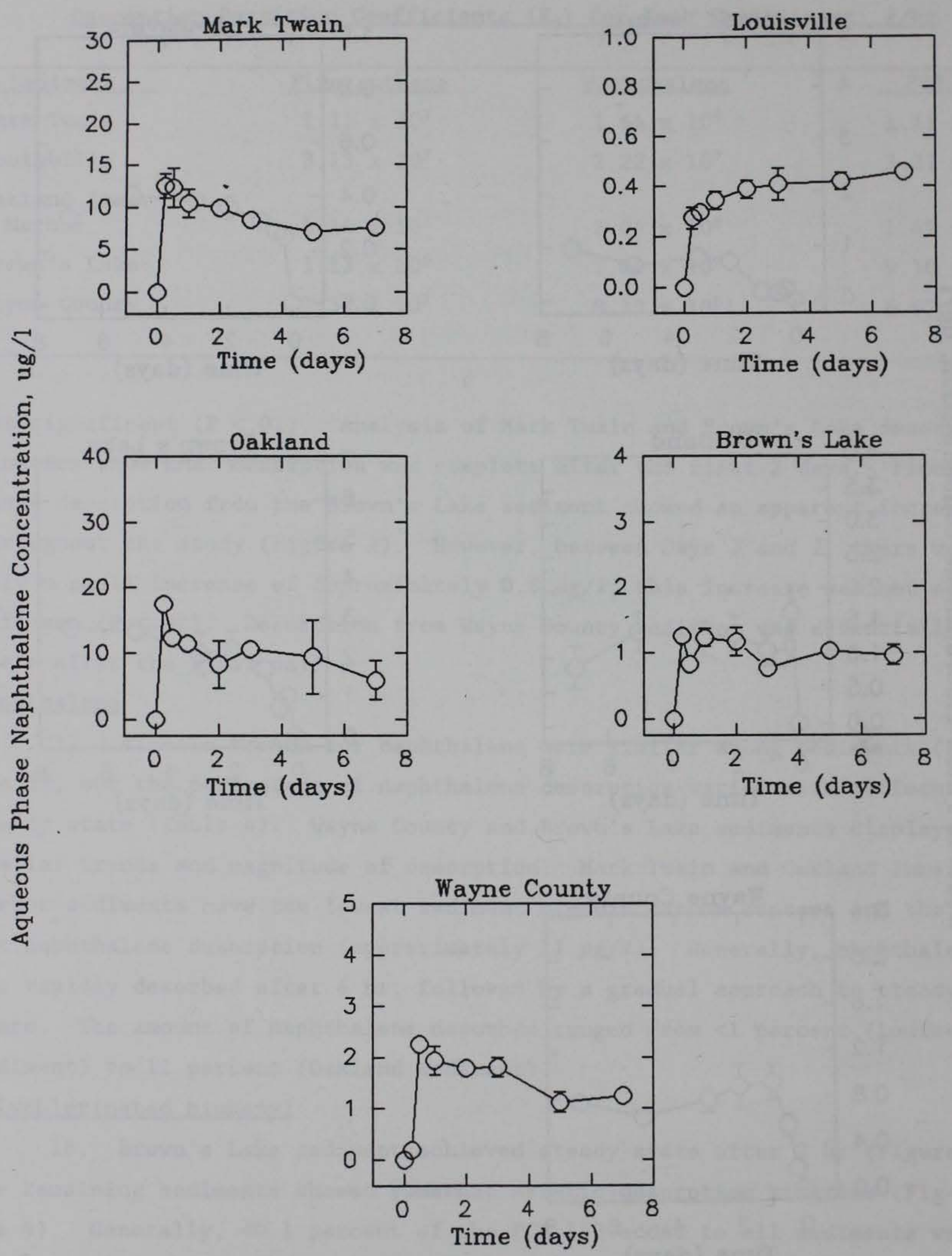

Figure 3. Kinetic curves for desorption of naphthalene 
Table 4

Percentage of Contaminant Desorbed from Each Sediment

\begin{tabular}{lccc}
\hline \multicolumn{1}{c}{ Sediment } & Fluoranthene & Naphthalene & $\frac{\text { PCB 151 }}{\text { Mark Twain }}$ \\
$\begin{array}{l}\text { Louisville } \\
\text { Oakland Inner }\end{array}$ & 1.0 & 11.0 & $<1.0$ \\
$\quad$ Harbor & 1.0 & $<1.0$ & $<1.0$ \\
Brown's Lake & 3.0 & 11.0 & $<1.0$ \\
Wayne County & $<1.0$ & 1.4 & $<1.0$ \\
& & 1.9 & 3.5 \\
\hline
\end{tabular}

probably resulted from facilitated transport of $\mathrm{PCB}$ into overlying water from colloidal material.

\section{Model Application}

\section{Fluoranthene}

19. Model estimates for fluoranthene desorption from Mark Twain and Oakland Inner Harbor sediments agreed with the experimental data (Figure 5). The values estimated for fluoranthene desorption from Mark Twain and Oakland Inner Harbor sediments were not significantly different from the values observed in the laboratory $(P<.01)$. Louisville, Browns's Lake, and Wayne County fluoranthene desorption kinetics were consistently underestimated by the model, but the trends displayed were similar to those observed in the laboratory.

Naphthalene

20. Estimated naphthalene desorption did not compare favorably with experimental data, especially for Louisville, Brown's Lake, and Wayne County sediments (Figure 6). The model tended to overpredict naphthalene desorption, and kinetic trends were dissimilar to those observed in the experimental data. For example, the predicted desorption kinetics for the Brown's Lake sediment was a slow and steady increase that reached equilibrium between Days 3 and 7 , at approximately $9 \mu \mathrm{g} / \ell$. The experimental data showed that equilibrium was reached within $24 \mathrm{hr}$ at approximately $0.3 \mu \mathrm{g} / \ell$. The model provided a better fit to the experimental naphthalene desorption data from Mark Twain and Oakland Inner Harbor sediments. The estimated naphthalene desorption values were 

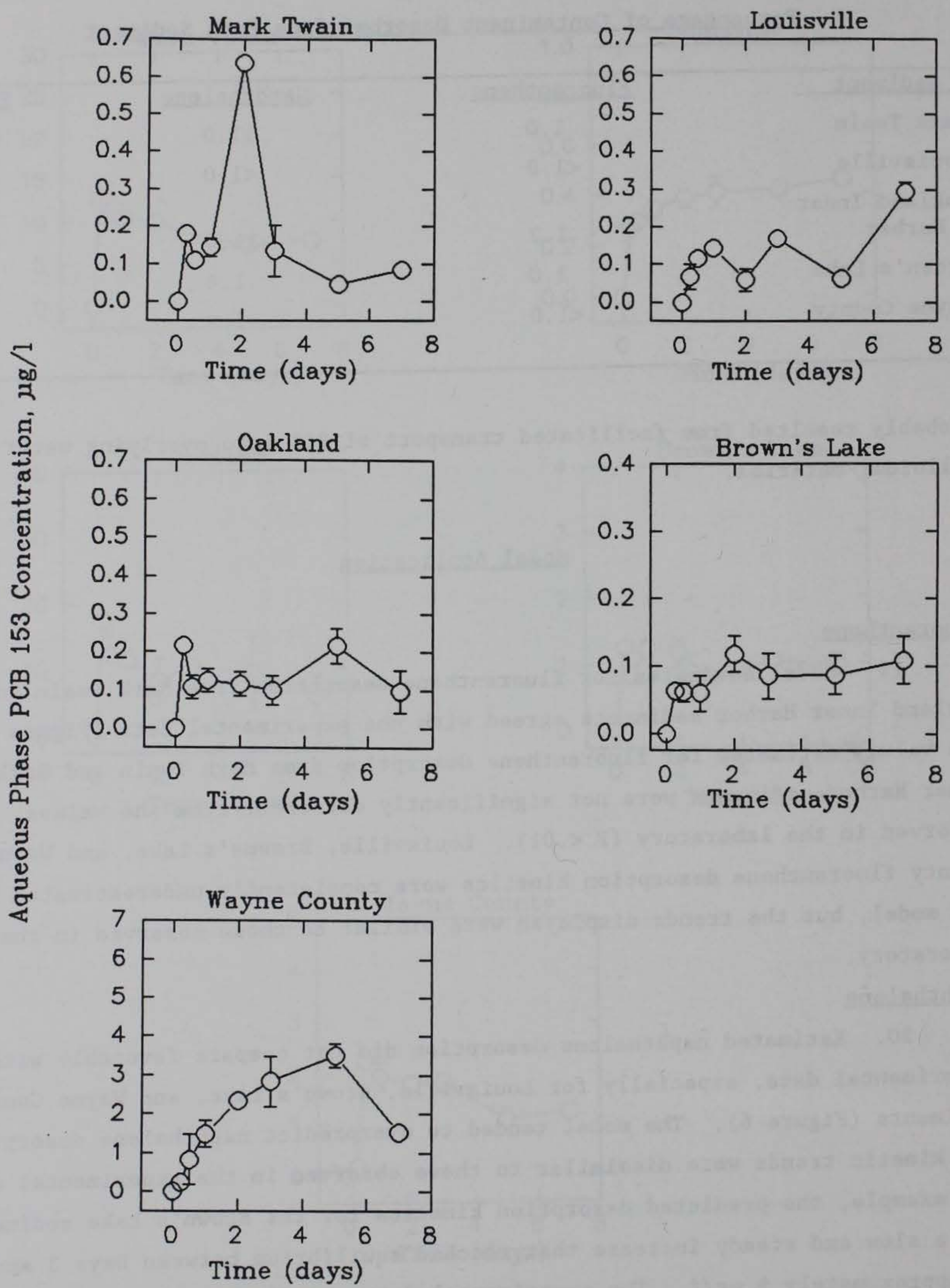

Figure 4. Kinetic curves for desorption of PCB 153 


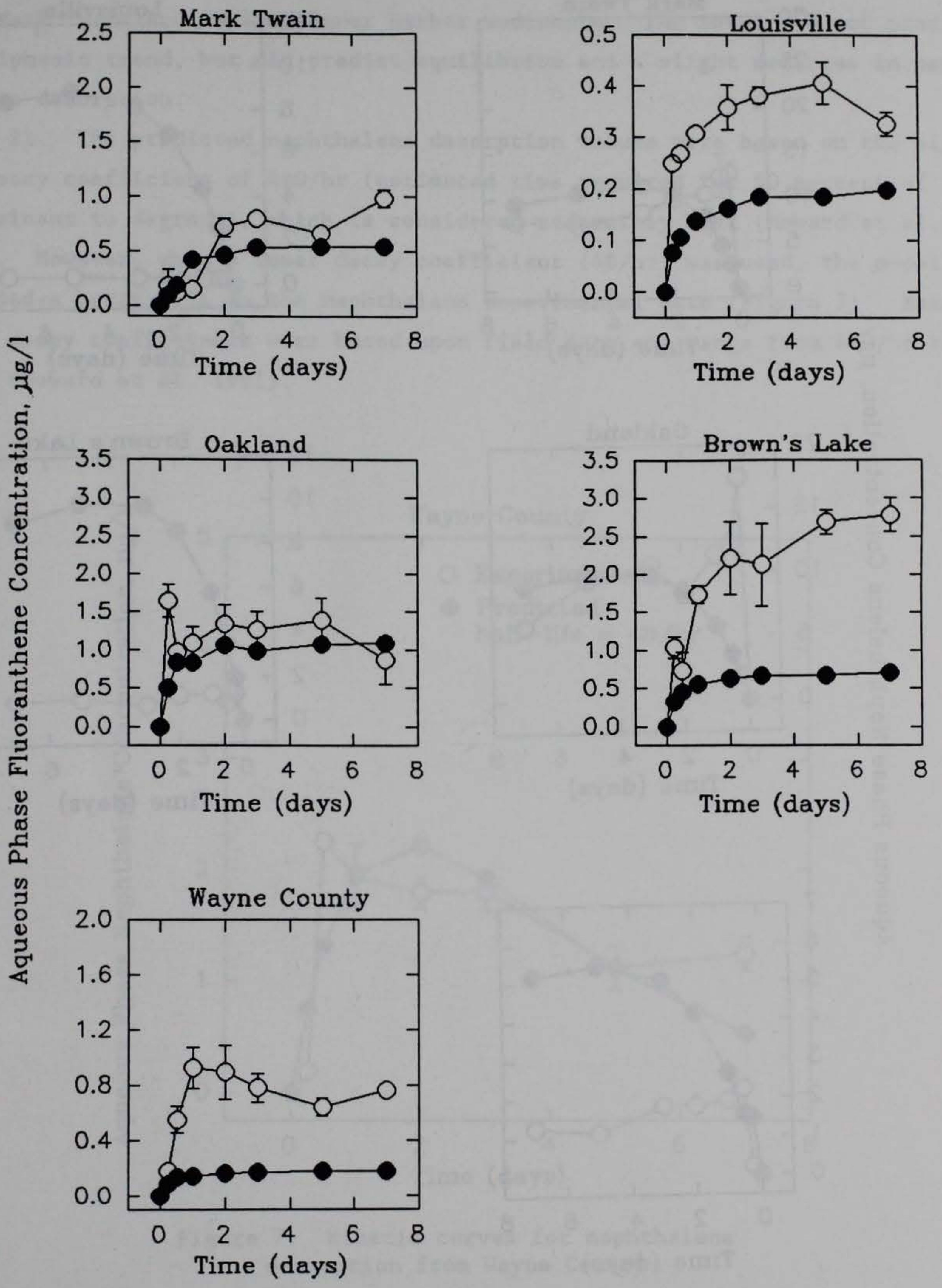

Figure 5. Experimental (hollow circle) and predicted (solid circle) kinetic curves for desorption of fluoranthene 

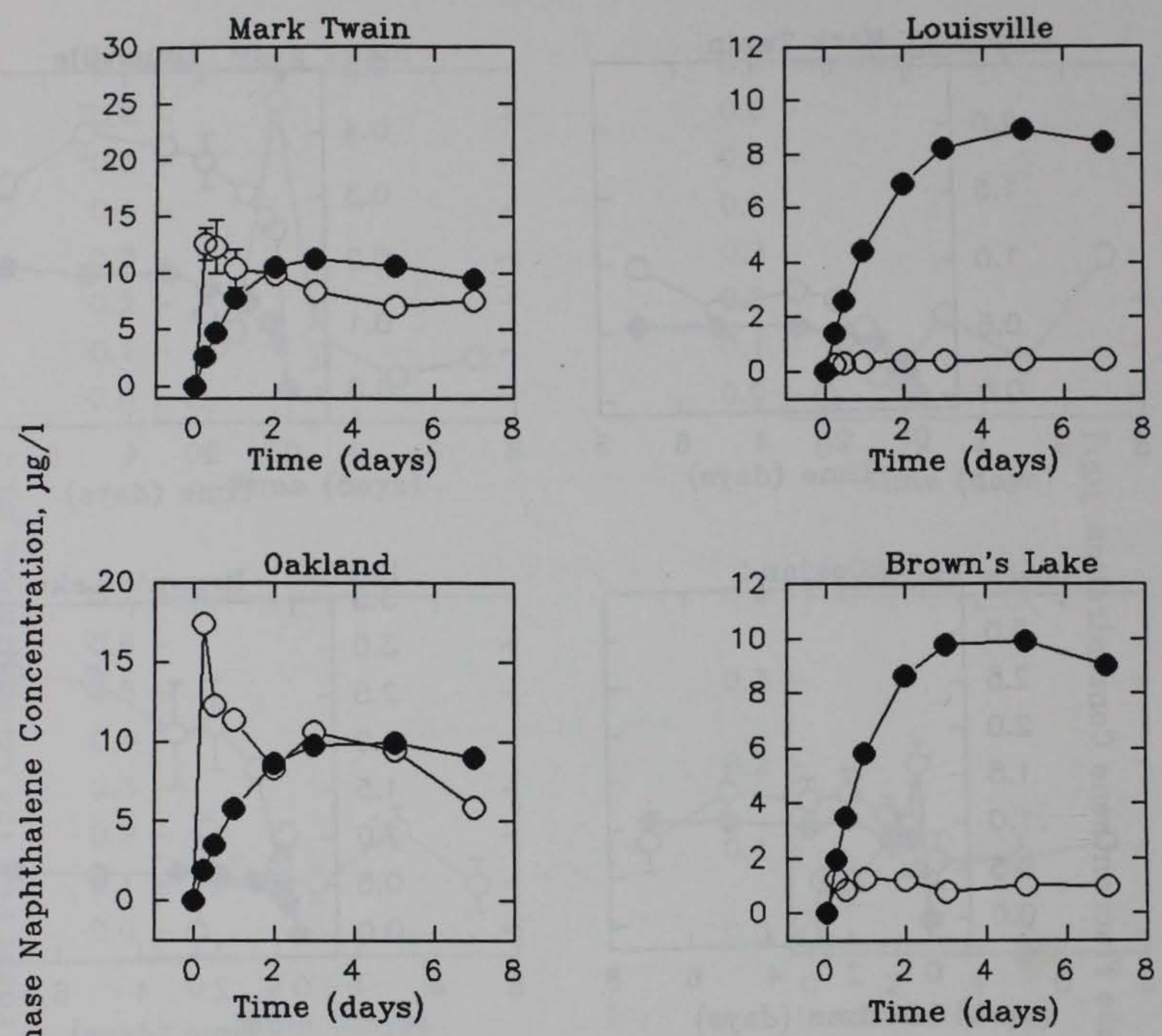

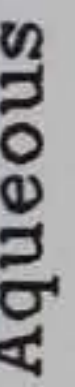

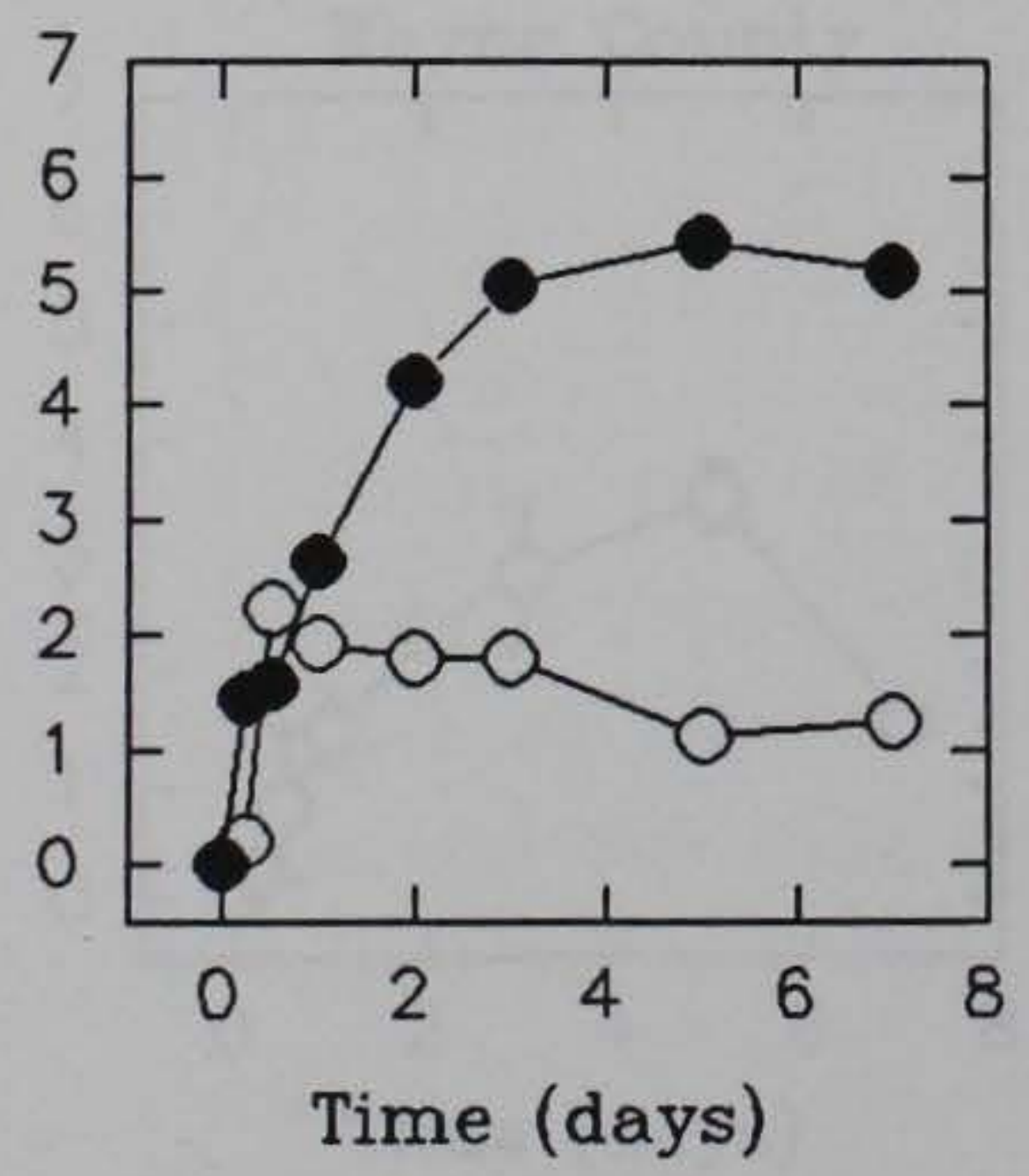

Figure 6. Experimental (hollow circle) and predicted (solid circle) kinetic curves for desorption of naphthalene 
not significantly different from the experimental values at equilibrium for both Mark Twain and Oakland Inner Harbor sediments. The model did not predict the biphasic trend, but did predict equilibrium and a slight decrease in naphthalene desorption.

21. The predicted naphthalene desorption values were based on the highest decay coefficient of $480 / \mathrm{hr}$ (estimated time required for 50 percent of contaminant to degrade), which is considered moderately fast (Howard et al. 1991). However, when a lower decay coefficient $(48 / \mathrm{hr})$ was used, the model provided a better fit to the naphthalene experimental data (Figure 7). Estimated decay coefficients were based upon field data and range from $480 / \mathrm{hr}$ to 12/hr (Howard et al. 1991).

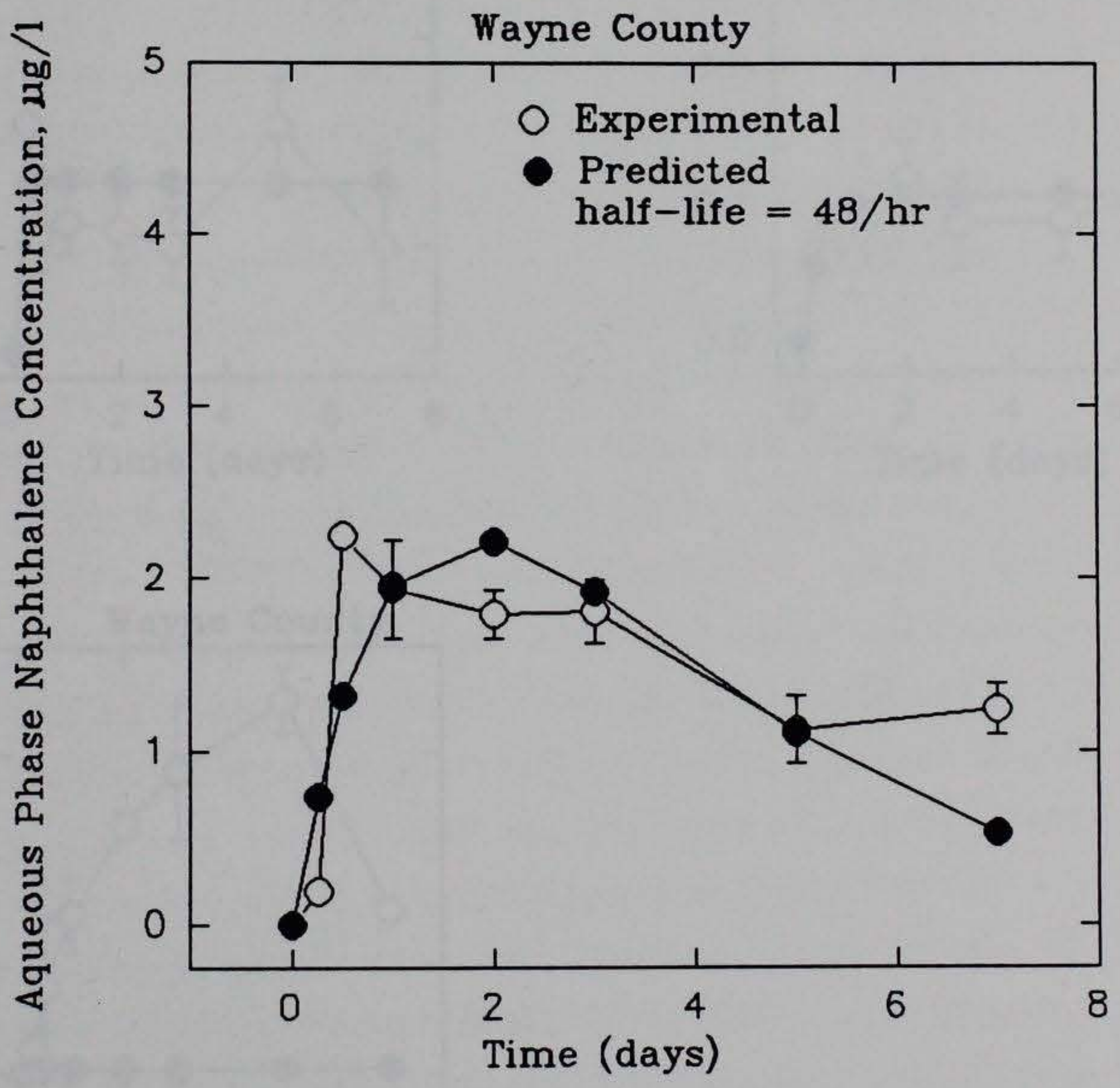

Figure 7. Kinetic curves for naphthalene desorption from Wayne County

$\underline{P C B}$

22. The predicted $\mathrm{PCB} 153$ desorption data provided a good fit with experimental data for all sediments except Wayne County (Figure 8). The problem with fitting the predicted data may be due to facilitated transport of PCB 
bound to colloidal organic matter. The model predicted the biphasic trend. Estimated values generated by the model were not significantly different from experimental values $(P<.01)$. Wayne county $P C B 153$ desorption values were underestimated by the model. 

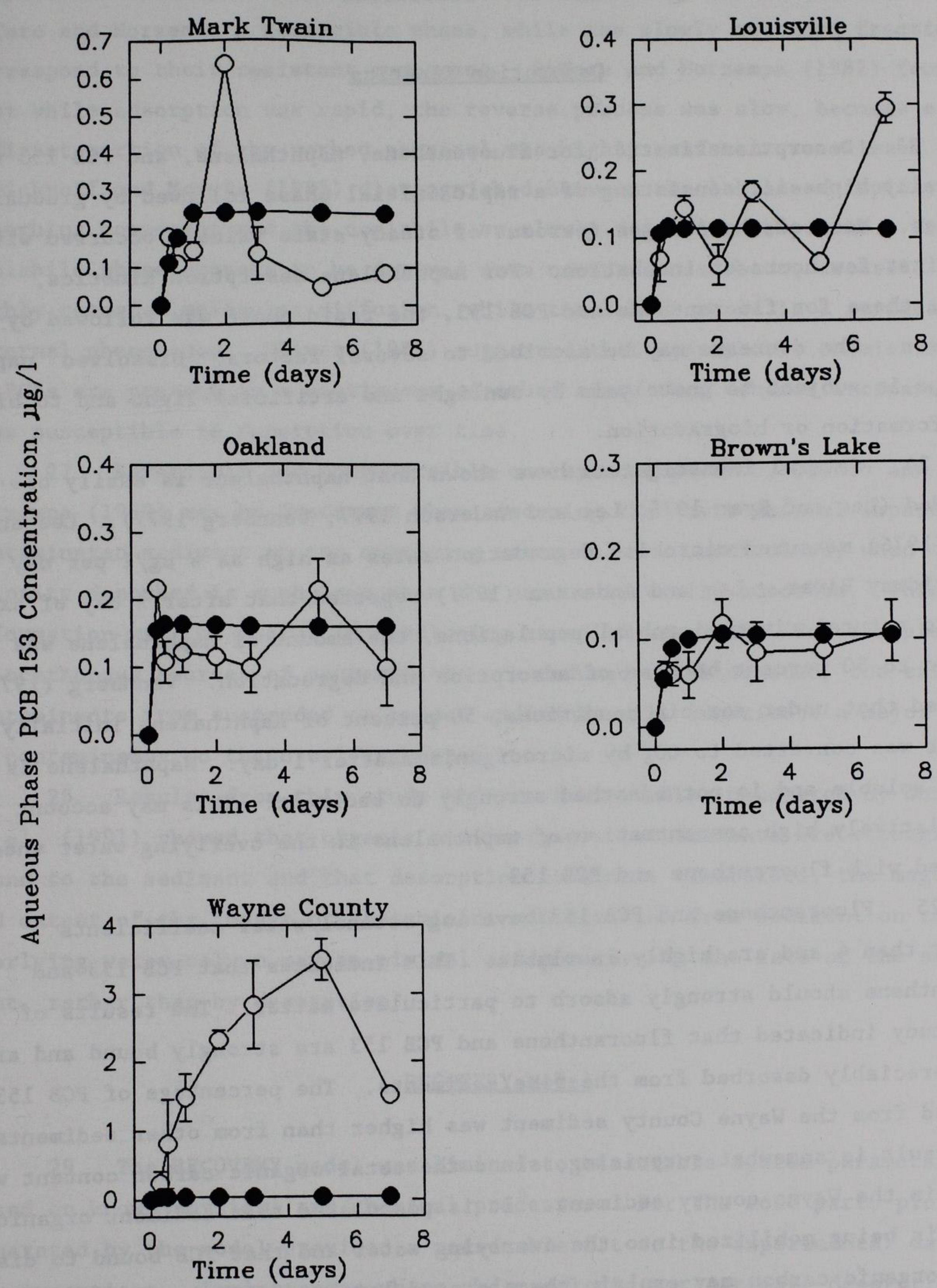

Figure 8. Experimental (hollow circle) and predicted (solid circle) kinetic curves for desorption of PCB 153 


\section{PART IV: DISCUSSION}

\section{Desorption Kinetics}

23. Desorption kinetics for fluoranthene, naphthalene, and PCB 153 were generally biphasic, consisting of a rapid initial phase followed by gradual changes. Most of the changes (percent of steady-state values) occurred within the first few hours of incubation. For naphthalene desorption kinetics, unlike those for fluoranthene and PCB 153, the rapid phase was followed by a decrease. The decrease may be ascribed to several factors. Dissolved naphthalene is subject to photolysis by sunlight and artificial light and to biotransformation or biogradation.

24. Several investigators have shown that naphthalene is easily biodegraded (Lee and Ryan 1976; Lee and Anderson 1977; Vennberg 1977). Lee and Ryan (1976) measured microbial degradation rates as high as $4 \mu \mathrm{g} / \ell$ per day in the Skidway River. Lee and Anderson (1977) reported that after 1 day of exposure to natural river microbial populations, the amount of naphthalene was reduced to 50 percent because of adsorption and degradation. Vennberg (1977) observed that under aerobic conditions, 50 percent of naphthalene initially present was converted to $\mathrm{CO}_{2}$ by microorganisms after 1 day. Naphthalene is highly soluble and is not adsorbed strongly to sediment. This may account for the relatively high concentration of naphthalene in the overlying water when compared with fluoranthene and PCB 153.

25. Fluoranthene and PCB 153 have log octanol/water coefficients greater than 4 and are highly insoluble. This indicates that PCB 153 and fluoranthene should strongly adsorb to particulate matter. The results of this study indicated that fluoranthene and PCB 153 are strongly bound and are not appreciably desorbed from the five sediments. The percentage of PCB 153 desorbed from the Wayne County sediment was higher than from other sediments. This result is somewhat surprising, since the total organic carbon content was higher in the Wayne county sediment. It is postulated that sediment organic matter is being mobilized into the overlying water and that PCB bound to dissolved organic carbon may explain the elevated levels of PCB in the overlying water (Wu and Gschwend 1986).

26. Fluoranthene and PCB 153 displayed a rapid desorption component followed by a slower component. DiToro and Horzempa (1982) found that PCB 153 had two components, a rapid reversible component and a resistant desorption 
component. The rapid component observed in this study may correspond to DiToro and Horzempa's reversible phase, while the slowly released fraction may correspond to their resistant component. DiToro and Horzempa (1982) found that while adsorption was rapid, the reverse process was slow, because a significant portion of the sorbed chemical was highly resistant to release. Karickhoff and Morris (1985) distinguished between the labile or rapidly desorbing component and the nonlabile or slowly desorbing component. The nonlabile phase appears to be derived from nonsurface sorbent, accessed by highly retarded molecular diffusion, while the labile phase is a surface or external phenomenon. Oliver (1985) suggested that hydrophobic chemicals such as PCBs are present in a continuous adsorbed state that becomes increasingly less susceptible to desorption over time.

27. Reversible and nonreversible concepts proposed by DiToro and Horzempa (1982) may be important when assessing the environmental impact of contaminated sediment on the overlying water column, particularly when the quantity desorbed is much less than the amount initially adsorbed. This information will be useful in developing remedial measures. For example, if allochthonous sources of contaminants are reduced or eliminated, the existing contaminants from suspended or bedded sediments will constitute a major source of contaminants to the overlying water.

28. Results from this study and previous studies conducted by Gunnison et al. (1991) showed that organic and inorganic contaminants are strongly bound to the sediment and that desorption is minor. Therefore, the magnitude and extent of the impact of contaminant mobilization from sediment on the overlying water column may be minimal and governed by the fate of the sediment, rather than by desorption.

\section{RECOVERY Mode1}

29. The RECOVERY model was limited to measurable system parameters, based on known physical and chemical processes. For the most part, plots generated by the model provided a reasonable fit to the experimental data with few exceptions. In instances where the model did not estimate desorption values, trends that were similar to those observed in the experimental data were predicted.

30. The RECOVERY model can be used to predict organic contaminant desorption. Incorporating easily measured or estimated parameters in the 
model enhanced and improved the capability for predicting desorption of organic contaminants from sediments. The overestimation of naphthalene desorption by the model may be ascribed to diffusion, high aqueous solubility of naphthalene, and the high decay coefficient input data. The high decay coefficient is recommended for naphthalene to predict worst-case conditions. This information is important. When appropriate management actions are taken to deal with worst-case conditions, such actions will also address less severe conditions.

31. Use of the model, model description and user's guide, and the data required to assess the potential impact of contaminated sediments on the overlying water using the RECOVERY model is found in Appendix A (Table A3). To apply the RECOVERY model, the user must provide data (i.e., hydrology, morphometry data, and system properties and compound properties) only if the contaminant under consideration is not listed in the model database.

32. To use RECOVERY to assess a site, the user should have sitespecific information such as contaminant concentration, flow, surface area, depth of water, depth of contaminated sediments, average suspended solids in the water, organic carbon content of water and sediments, sediment particle size, and sediment porosity. In addition, information that may be more difficult to obtain but necessary includes resuspension velocity, burial velocity, and settling velocity of sediment. However, only two of the values are needed; the third value will be estimated by the model from a solids mass balance. Settling velocities can be estimated by determining an average particle size (from grain size analysis data) and then using Stokes' Law to estimate settling velocity for the average particle. Burial velocities can be estimated from long-term average deposition rates or from sediment dating.

33. The last group of data needed to run RECOVERY is properties of the specific contaminant. The RECOVERY model contains some of this information for compounds in its database (See Appendix A for list of compounds in the database). Three properties, Henry's constant, octanol-water partition coefficient, and molecular weight, are in the database. Molecular diffusivity and decay coefficients must be estimated from laboratory data or from the literature. Molecular diffusivity has a default value of $10^{-5} \mathrm{~cm}^{2} / \mathrm{sec}$. One source for decay coefficients is the Handbook of Environmental Degradation Rates. Groundwater Chemicals Desk Reference and US Environmental Protection Agency (1979) are excellent references for obtaining compound properties needed for a RECOVERY application. 
34. The $K_{d}$ values determined experimentally indicate that desorption was minor for all contaminants tested. The quantity of chemical desorbed was much less ( $<1$ to 11 percent) than the quantity initially adsorbed to the sediment. Therefore, the environmental fate of adsorbed fluoranthene and PCB 153 will be dictated by the transport fate of the sediment rather than by desorption. These results are consistent with adsorption/desorption results of Gunnison et al. (1991). Gunnison et al. (1991) showed that PCB 151 became tightly bound to the sediment and that long-term effects of desorption on mobilization of PCB 151 would be minimal. They also showed that an inverse relationship existed between $\mathrm{K}_{d}$ and sediment concentration. Therefore, results from present and past studies suggest that an equilibrium approach is appropriate for describing bed sediment interactions with the overlying water for organic contaminants.

35. Partitioning models in which equilibrium between sorbed and dissolved species is assumed are sufficient to provide management level estimates of the fate of contaminants. The RECOVERY model, which assumes that contaminants follow linear equilibrium sorption and first-order decay kinetics, is an effective tool that can be used to predict organic contaminant desorption. This information can be used by the USACE to assess the potential impacts of contaminated sediment on the overlying water column of specific reservoir projects. 


\section{REFERENCES}

Banks, R. B. 1975. "Some Features of Wind Action on Shallow Lakes," J. Environ. Engr. Div, ASCE, Vol 101 (EE5), pp 813-827.

Banks, R. B., and Herrera, F. F. 1977. "Effect of Wind and Rain on Surface Reaeration," J. Environ. Engr. Div. ASCE, Vol 103 (EE3), Princeton, NJ.

Berner, R. A. 1980. Early Diagenesis, Princeton University Press, Princeton, NJ .

Boyer, J. M., and Chapra, S. C. 1989. "A Mathematical Model to Predict the Temporal Responses of a Surface Water to Contaminated Sediments, "prepared by the University of Colorado Center for Advanced Decision for Water and Environmental Support Systems for the New England Division and US Army Engineer Waterways Experiment Station.

Chapra, S. C. 1982. "Long-Term Models of Interactions between Solids and Contaminants in Lakes," PhD Dissertation, The University of Michigan, Ann Arbor, MI.

. 1986. "Toxic Substances Modeling," In Intensive Course Notes: Mathematical Modeling of Lake and Reservoir Water Quality. Duke University School of Forestry and Environmental Studies, Durham, NC.

Chapra, S. C., and Canale, R. P. 1988. Numerical Methods for Engineers, McGraw-Hill, New York.

Chapra, S. C., and Reckhow, K. H. 1983. Engineering Approaches for Lake Management, Vol 2: Mechanistic Modeling. Ann Arbor Science/Butterworth, Woburn, MA.

DiToro, D. M. , and Horzempa, L. M. 1982. "Reversible and Resistant Compounds Components of PCB Adsorption-Desorption: Isotherms," Environmental Science and Technology, Vol 16, p 595.

Gunnison, D., Sturgis, T. C., Pennington, J. C., Brannon, J. M., Mills, A. L., Lehman, M. , and Blum, L. K. 1991. "Studies on the Adsorption/Desorption and Microbial Mobilization of Contaminants from Sediments in Corps of Engineers Reservoir Projects," Miscellaneous Paper W-91-1, US Army Engineer Waterways Experiment Station, Vicksburg, MS.

Hamaker, J. W., and Thompson, J. M. 1972. "Adsorption," In Organic Chemicals in the Soil Environment, C. A. I. Goring and J. W. Hamaker, eds., Vol 1, pp 49-143, Dekker, New York.

Howard, P. H., Boethling, R. S., Jarvis, W. F., Meylan, W. M., and Michalenko, E. M. 1991. Handbook of Environmental Degradation Rates. Heather Taub, ed., Lewis Publishers, MI.

Karickhoff, S. W., Brown, D. S., and Scott, T. A. 1979. "Sorption of Hydrophobic Pollutants on Natural Sediments," Water Research, Vol 13, pp 241-248.

Karickhoff, S. W., and Morris, K. R. 1985. "Sorption Dynamics of Hydrophobic Pollutants in Sediment Suspensions," Environmental Toxicology and Chemistry. Vol 4, pp 469-479.

Lee, R. F., and Anderson, J. W. 1977. "Fate and Effect of Naphthalene: Controlled Ecosystem Pollution Experiment," Bull. Mar. Sci.. Vol 27. 
Lee, R. F., and Ryan, C. 1976. "Biodegradation of Petroleum Hydrocarbons by Marine Microbes, " In Proceedings of the Third International Conference on Biodegradation. Applied Science Publishers, London.

Leo, A., and Elkins, D. 1971. "Partition Coefficients and Their Uses," Chem Rev. Vol 71, pp 525-616.

Lyman, W. J., Rheeh1, W. F., and Rosenblatt, D. H., eds. 1982. Handbook of Chemical Property Estimation Methods, McGraw-Hill, New York.

Manheim, F. T., and Waterman, L. S. 1974. "Diffusimetry (Diffusion Constant Estimation) on Sediment Cores by Resistivity Probe," Initial Report of the Deep Sea Drilling Project, Vol 22, pp 663-670.

McFarland, V. A., Clarke, J. U., and Gibson, A. B. 1986. "Changing Concepts and Improved Methods for Evaluating the Importance of PCBs as Dredged Sediment Contaminants," Miscellaneous Paper D-86-5, US Army Engineer Waterways Experiment Station, Vicksburg, MS .

Mills, w. B., Porcella, D. B., Ungs, M. J., Gherini, S. A., Summers, K. V., Lingfung, Mok, Rupp, G. L., Bowie, G. L., and Haith, D. A. 1982. "Water Quality Assessment: A Screening Procedure for Toxic and Conventional Pollutants, Part I," Tetra Tech, Inc., Env. Res. Lab., Office of Research and Devel., USEPA, EPA-600/6-82-004a, Athens, GA.

Neeley, W. B., and Blau, G. E. 1977. "The Use of Laboratory Data to Predict the Distribution of Chlorpyrifos in a Fish Pond," Pesticides in the Aquatic Environment. Plenum Press, New York, pp 145-163.

Oliver, B. C. 1985. "Desorption of Chlorinated Hydrocarbons from Spiked and Anthropogenically Contaminated Sediments, " Chemosphere, Vol 14 (8), pp 1087-1106.

Press, W. B., Flannery, B. P., Teukolsky, S. A., and Vetterling, W. T. 1986. Numerical Recipes: The Art of Scientific Computing. Cambridge University Press, Cambridge, MA.

Radding, S. B., Mill, T., Gould, C. W., Liu, D. H., Johnson, H. L., Bomberger, D. S., and Fojo, C. V. 1976. "The Environmental Fate of Selected Polynuclear Aromatic Hydrocarbons," US Environmental Protection Agency, EPA 560/5-755-009, Office of Toxic Substances, Washington, DC.

Schnoor, J. L., Sato, Chikashi, McKechnie, Deborah, and Sahoo, Dipak. 1987. "Processes, Coefficients, and Models for Simulating Toxic Organics and Heavy Metals in Surface Waters," Envir. Res. Lab., Office of Research and Development USEPA, EPA/600/3-87/015, Athens, GA.

Thomann, R. V., and Mueller, J. A. 1987. Principles of Surface Water Quality Modeling and Control, Harper and Row, New York.

US Environmental Protection Agency. 1979 (Dec). "Water Related Environmental Fate of 129 Priority Pollutants," EPA-440/479-029b, Vol 2, Washington, DC.

Vennberg, F. J. 1977. "Physiological Response of Marine Biota to Pollutants," pp 323-340, Academic Press, New York.

Watanabe, N. 1985. "Adsorption and Desorption of Polydimethylsiloxane, PCBs, Cadmium Nitrate, Copper Sulfate, Nickel Sulfate and Zinc Nitrate by River Surface Sediments," The Science of the Total Environment, Vol 41, pp 153-161. 
Wu, Shian-chee, and Gschwend, Phillip M. 1986. "Sorption Kinetics of Hydrophobic Organic Compounds to Natural Sediments, "Environ. Sci. Technol.. Vol 20, pp 717-725. 
APPENDIX A: RECOVERY MODEL DESCRIPTION, USER'S GUIDE, AND INSTALLATION AND RUN 
1. The RECOVERY model is an application and extension of frameworks developed previously (Chapra 1982, 1986, and Chapra and Reckhow 1983).* As in Figures $A 1$ and $A 2$, the system is idealized as a well-mixed surface water layer, underlain by a vertically stratified sediment column. The sediment is well mixed horizontally, but segmented vertically into a well-mixed surface layer and a deep sediment. The latter, in turn, is segmented into contaminated and uncontaminated regions. The specification of a mixed surface layer is included because an unconsolidated layer is often observed at the surface of sediments because of such processes as bioturbation and mechanical mixing.

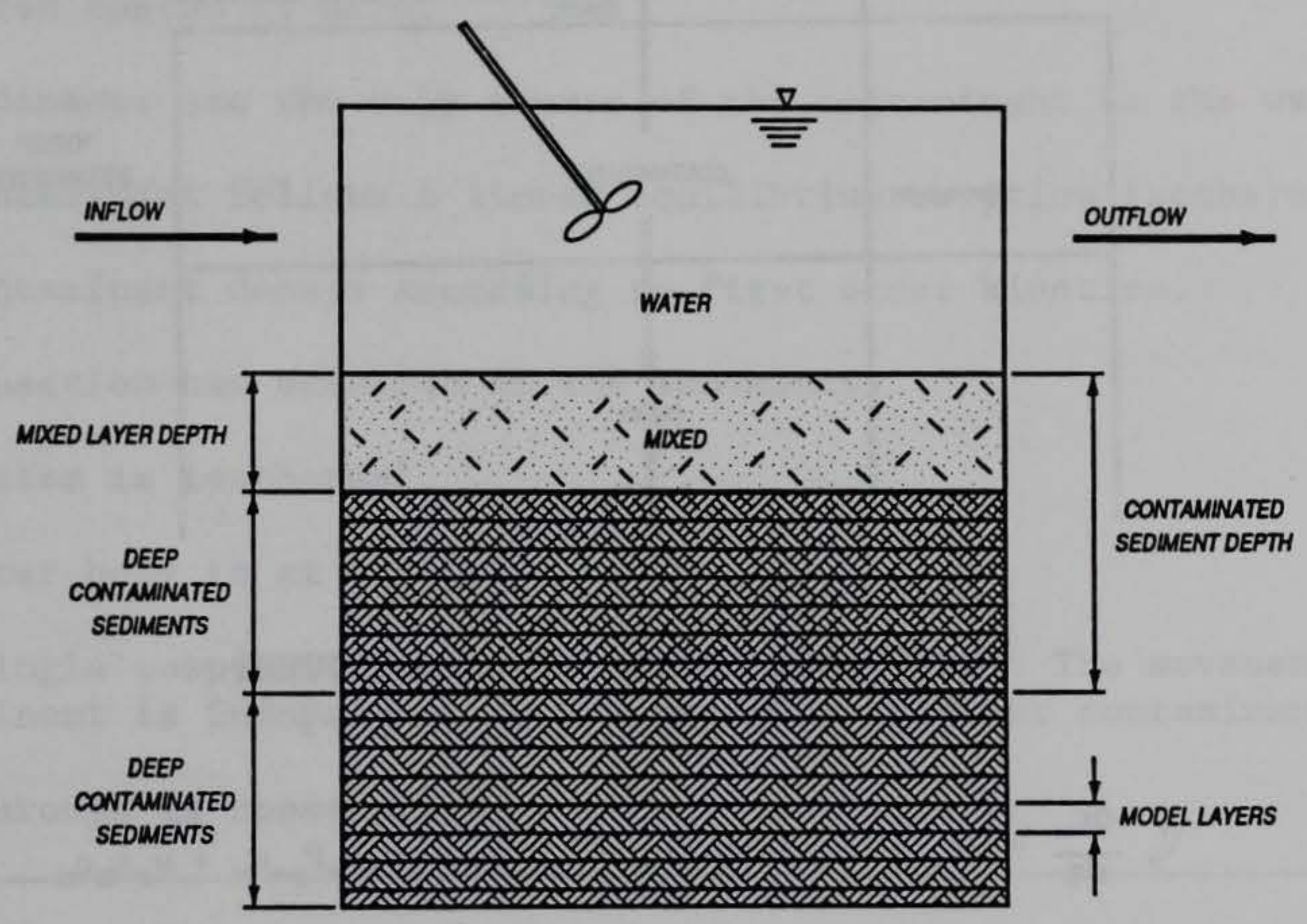

Figure Al. Physical configuration of RECOVERY

2. A list of assumptions used in the development of this model is included (Table Al).

\section{Contaminant Mass Balances}

3. A mass balance for the contaminant in the water can be written as

* References cited in this appendix are included in the References at the end of the main text. 


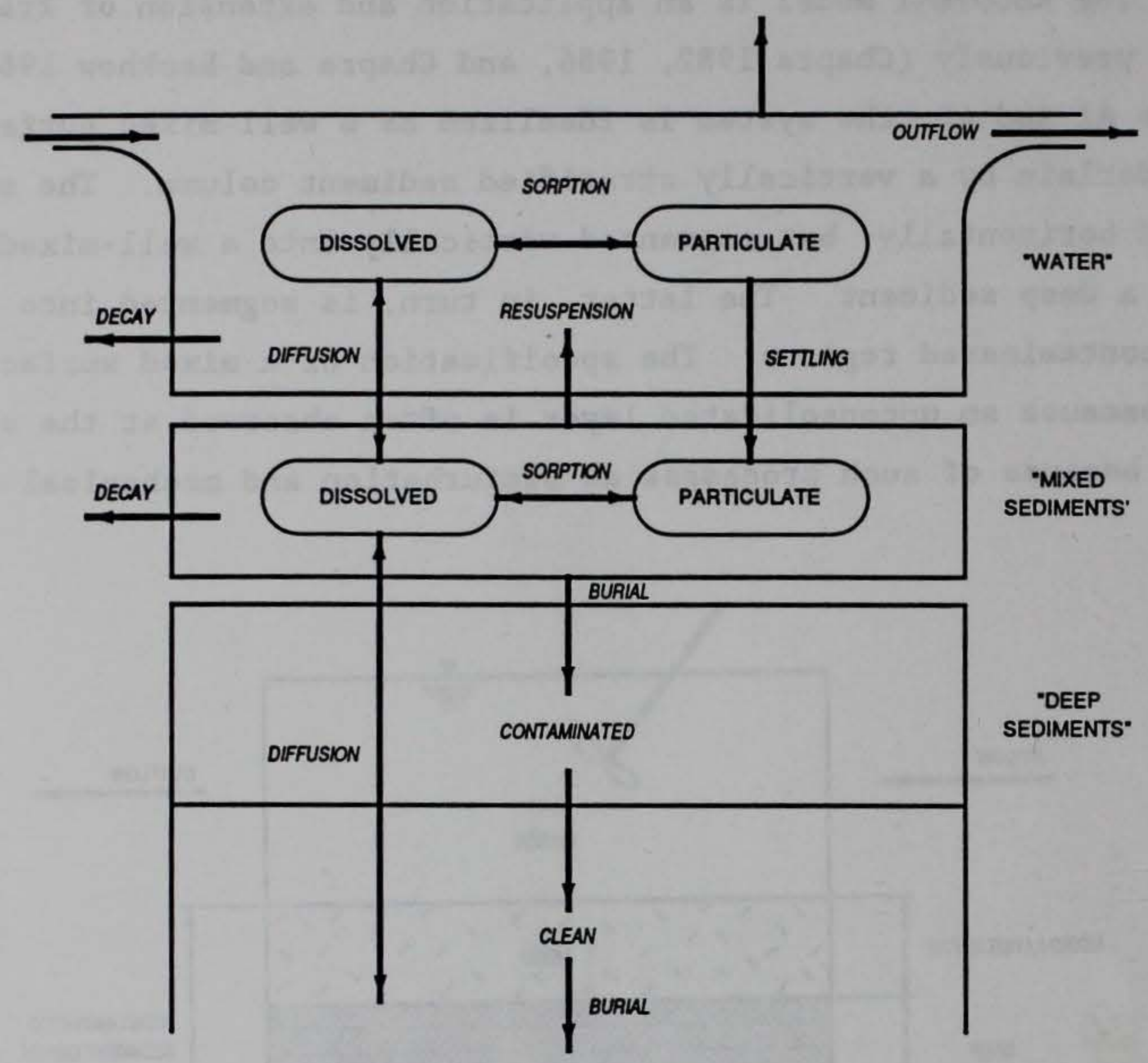

Figure A2. Schematic of RECOVERY

$$
\begin{gathered}
V_{w} \frac{d c_{w}}{d t}=Q c_{i}-Q c_{w}-k_{w} V_{w} c_{w}-k_{v} V_{w} c_{w}-\nu_{s} A_{w} F_{p w} c_{w}+\nu_{r} A_{m} c_{m} \\
+\nu_{d} A_{m}\left(F_{d p} c_{m}-F_{d w} c_{w}\right)
\end{gathered}
$$

where

$$
\mathrm{V}_{\mathrm{w}}=\text { volume of water body, } \mathrm{m}^{3}
$$

$c_{w}$ and $c_{m}=$ concentrations of toxicant in water and mixed sediments, respectively, $\mu \mathrm{g} / \mathrm{m}^{3}$

$t=$ time, years

$Q=$ flushing flow rate, $\mathrm{m}^{3} /$ year

$c_{i}=$ inflow concentration, $\mu \mathrm{g} / \mathrm{m}^{3}$, which reflects both direct and tributary loadings (in the present version of the model, this concentration is assumed to be zero) 
1. Contaminant is of organic nature.

2. The water body is well mixed.

3. The "mixed" layer is well mixed.

4. In the deep sediments, contaminant concentration varies in the vertical direction only.

5. The initial concentration of the contaminant in the contaminated region is uniform throughout the region.

6. The initial concentration of the contaminant in the region below the contaminated region is zero.

7. The sediments are the only source of the contaminant to the water body.

8. The contaminant follows a linear equilibrium sorption isotherm.

9. The contaminant decays according to first order kinetics.

10. No compaction has occurred in the sediments.

11. The system is isothermal.

12. The water body is at $25^{\circ} \mathrm{C}$.

13. Only single component mass transfer is described. The movement of the contaminant is independent of the presence of other contaminants.

14. Flow-through is constant.

$k_{w}=$ decay rate constant of the contaminant in the water, per year

$\mathrm{k}_{\nu}=$ volatilization rate of contaminant, per year

$\nu_{\mathrm{s}}=$ settling velocity of particulate matter, m/year

$A_{w}$ and $A_{m}=$ surface areas of water and mixed sediment, respectively, $\mathrm{m}^{2}$

$F_{\mathrm{pw}}=$ fraction of contaminant in particulate form in the water

$\nu_{\mathbf{r}}=$ resuspension velocity of sediments, m/year

$\nu_{\mathrm{d}}=$ diffusion mass transfer coefficient at the sediment-water interface, $\mathrm{m} /$ year

$F_{d p}=$ ratio of contaminant concentration in the sediment pore water to contaminant concentration in total sediment

$F_{d w}=$ fraction of contaminant in the dissolved form in the water 
4. The initial condition for Equation 1 is at $t=0, c_{w}-c_{w 0}\left(c_{w 0}=\right.$ initial concentration of contaminant in water).

5. A mass balance for the mixed-sediment layer can be written as

$$
\begin{aligned}
V_{m} \frac{d c_{m}}{d t}=-k_{m} V_{m} c_{m}+\nu_{s} A_{w} F_{p w} c_{w}-\nu_{r} A_{m} c_{m}-\nu_{b} A_{m} c_{m}+\nu_{d} A_{m}\left(F_{d w} c_{w}-F_{d p} c_{m}\right) \\
+\nu_{d} A_{m}\left(F_{d p} c_{s}(0)-F_{d p} c_{m}\right)
\end{aligned}
$$

where

$\mathrm{V}_{\mathrm{m}}=$ volume of mixed layer, $\mathrm{m}^{3}$

$k_{m}=$ decay rate constant of the contaminant in the mixed layer, per year

$\nu_{\mathrm{b}}=$ burial velocity, m/year

$c_{s}(0)=$ contaminant concentration at the top of the deep contaminated layer, $\mu \mathrm{g} / \mathrm{m}^{3}$

6. The initial condition for this equation is at $t=0, c_{m}=c_{m o}$ ( $c_{m o}=$ initial concentration of contaminant in the mixed layer).

7. Both the deep contaminated and clean sediments can be modeled with one-dimensional advection-diffusion-decay equations of the form:

$$
\frac{\partial c_{s}}{\partial t}=\phi F_{d p} D_{s} \frac{\partial^{2} c_{s}}{\partial z^{2}}-\nu_{b} \frac{\partial c_{s}}{\partial z}-k_{s} c_{s}
$$

where

$c_{s}=$ contaminant concentration in the deep sediments, $\mu \mathrm{g} / \mathrm{m}^{3}$

$\phi=$ sediment porosity

$D_{s}=$ diffusion rate in the sediment pore water, $\mathrm{m}^{2} /$ year

$z=$ depth into the sediment, $m$, where $z=0$ at the top of the deep sediments

$k_{s}=$ decay rate constant of the contaminant in the deep sediments, per year

8. The initial and boundary conditions for Equation 3 are:

IC: at $t=0, \quad c_{s}=c_{s o} \quad\left(z_{m}<z<L\right)$

IC: at $t=0, \quad c_{s}=0 \quad(L<z<\infty)$

BC 1: at $z=z_{m}, J=J_{m s}$ 
BC 2: at $z=\infty, \quad \frac{\partial c_{s}}{\partial z}=0$

where $\mathrm{L}$ - distance from the top of the mixed layer to the bottom of the contaminated layer, $\mathrm{J}=$ mass flux of the contaminant, $\mathrm{g} /\left(\mathrm{m}^{2}-\mathrm{yr}\right), \mathrm{J}_{\mathrm{ms}}=$ mass flux of the contaminant from the mixed layer to the sediment layer, $\mathrm{g} /\left(\mathrm{m}^{2}-\mathrm{yr}\right)$, and $c_{\text {so }}=$ initial concentration of contaminant in the deep sediment layer.

9. The F's in Equations 1-3 are dimensionless ratios that reflect how the contaminant partitions between solid matter and water, assuming a linear sorption mechanism. Denoting the contaminant as $\mathrm{A}$, they are defined as

$$
\begin{aligned}
F_{p w} & =\frac{K_{d w} S_{w}}{1+K_{d w} S_{w}} \\
& =\left(\frac{\text { Mass of A ( Particulate Form) }}{\frac{\text { Total Volume }}{\text { Mass of A (Dissolved Form) + Mass of A (Particulate Form) }}}\right)
\end{aligned}
$$

$$
F_{d w}=1-F_{p w}=\frac{1}{1+K_{d w} S_{w}}
$$

$$
=\left(\frac{\frac{\text { Mass of A (Dissolved Form ) }}{\text { Total Volume }}}{\frac{\text { Mass of A (Dissolved Form })+ \text { Mass of A (Particulate Form) }}{\text { Total Volume }}}\right)_{\text {Water Body }}
$$

$$
F_{\mathrm{dp}}=\frac{1}{\phi+\mathrm{K}_{\mathrm{ds}}(1-\phi) \rho}
$$

$=\left(\frac{\frac{\text { Mass of A (Dissolved Form ) }}{\text { Volume of Pore Water }}}{\frac{\text { Mass of A (Dissolved Form) + Mass of A (Particulate Form) }}{\text { Total Volume }}}\right)_{\text {Sediment }}$

where 
$\mathrm{K}_{\mathrm{dw}}$ and $\mathrm{K}_{\mathrm{ds}}$ = contaminant partition coefficient in the water and sediments, respectively, $\mathrm{m}^{3} / \mathrm{g}$

$s_{w}=$ suspended solids concentration in the water, $\mathrm{g} / \mathrm{m}^{3}$

$\rho=$ density of sediment solids, $\mathrm{g} / \mathrm{m}^{3}$

Note that the model allows different values of this parameter to be employed in the mixed layer and the vertically segmented sediments ( $F_{d p m}$ and $F_{d p s}$ ).

10. The decay rate constants $k_{w}, k_{m}$, and $k_{s}$, represent all mechanisms for decay except volatilization, which is accounted for separately. These mechanisms include photolysis, hydrolysis, and bacterial degradation.

11. The mass transfer coefficient for diffusive sediment-water exchange is related to more fundamental parameters by

$$
\nu_{\mathrm{d}}=\frac{\phi \mathrm{D}_{\mathrm{s}}}{\mathrm{z}^{\prime}}
$$

where

$$
\begin{aligned}
\phi= & \text { porosity } \\
D_{s}= & \text { diffusion coefficient in the sediment pore water, } \mathrm{m}^{2} / \text { year } \\
z^{\prime}= & \text { characteristic length over which the gradient exists at the } \\
& \text { sediment-water interface, } m
\end{aligned}
$$

Note that a value of $1 \mathrm{~cm}$ is assumed for $z^{\prime}$ after Thomann and Mueller (1987). Also, $D_{s}$ is related to molecular diffusivity $D_{m}$ by the relation (Berner 1980; Manheim and Waterman 1974)

$$
D_{s}=D_{m} \phi^{2}
$$

\section{Solids Budget}

12. The velocity terms- $-\nu_{s}, \nu_{r}$, and $\nu_{b}--$ in Equations 1 and 2 are computed according to a steady-state mass balance for mixed-sediment layer solids as described by Chapra and Reckhow (1983). The mass balance is

$$
0=\nu_{\mathrm{s}} \mathrm{A}_{\mathrm{w}} \mathrm{S}_{\mathrm{w}}-\left(\nu_{\mathrm{r}}+\nu_{\mathrm{b}}\right) \mathrm{A}_{\mathrm{w}}(1-\phi) \rho_{\mathrm{p}}
$$


13. The framework assumes that suspended solids concentration $s_{w}$ is given. Therefore, if two of the three velocities are specified, Equation 9 can be employed to calculate the third.

14. In addition to these transfer velocities, the other facet of the model related to the solids budget is the sediment porosity. Different porosities are allowed for the mixed layer and the deep sediments. Within these regions, porosity is constant. This means that compaction is not included and has no impact on the accuracy of the model.

\section{Default Parameters}

15. Several parameters in the above framework are provided by the software as default values. These are suggested values that represent first estimates and can be easily modified by the user.

\section{Volatilization rate}

16. The volatilization rate is computed by

$$
\mathrm{k}_{\mathrm{v}}=\mathrm{F}_{\mathrm{dw}} \frac{\nu_{\mathrm{v}}}{\mathrm{Z}_{\mathrm{w}}}
$$

where $\nu_{v}=$ a volatilization transfer coefficient, m/year, which can be computed according to the Whitman two-film theory as

$$
\nu_{v}=\frac{\mathrm{K}_{1} \mathrm{~K}_{8} \mathrm{H}_{e}}{\mathrm{~K}_{8} \mathrm{H}_{e}+\mathrm{K}_{1}}
$$

where $\mathrm{H}_{\mathrm{e}}=$ a dimensionless Henry's coefficient that is related to the common form, $\mathrm{H}_{\mathbf{e}^{\prime}}$, atm $\mathrm{m}^{3} / \mathrm{mole}$, by

$$
H_{e}=\frac{H_{e^{\prime}}}{R T}
$$

where

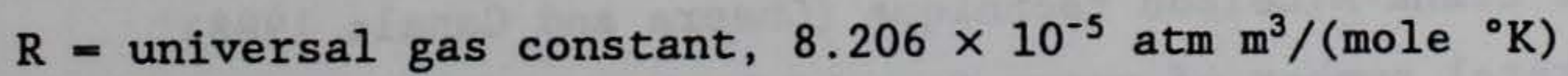

$$
\begin{aligned}
& \mathrm{T}=\text { absolute temperature, }{ }^{\circ} \mathrm{K}
\end{aligned}
$$

A temperature of $298^{\circ} \mathrm{K}\left(25^{\circ} \mathrm{C}\right)$ is assumed in the model. 
17. The parameter $\mathrm{K}_{\mathrm{B}}$ is a gas-film mass transfer coefficient (meters per year) that can be related to wind speed, $U_{w}$ (meters per second), and molecular weight, MW (grams per gram mole), by (Mills et al. 1982)

$$
\mathrm{K}_{\mathrm{B}}=61320\left(\frac{18}{\mathrm{MW}}\right)^{0.25} \mathrm{U}_{\mathrm{w}}
$$

18. The parameter $\mathrm{K}_{1}$ is a liquid-film mass transfer coefficient (milligrams per year) that can be related to wind speed, $U_{w}$ (meters per second), and molecular weight, MW (grams per gram mole), by (Mills et al. 1982; Banks 1975; Banks and Herrera 1977)

$$
K_{1}=365\left(\frac{32}{M W}\right)^{0.25}\left(0.728 U_{w}^{0.5}-0.317 U_{w}+0.0372 U_{w}^{2}\right)
$$

\section{Partition coefficient}

19. The partition coefficient for organic contaminants is computed via (Karichhoff et al. 1979)

$$
K_{d}=0.617 f_{o c} K_{o w}
$$

where

$f_{o c}=$ weight fraction of organic carbon in the solid matter, $g$-orgC/g $\mathrm{k}_{\text {ow }}=$ octanol-water partition coefficient, $\left(\mathrm{mg} / \mathrm{m}^{3}\right.$-octanol $) /\left(\mathrm{mg} / \mathrm{m}^{3}\right.$-water $)$ Note that the model assumes a default of 0.05 for $f_{o c}$.

\section{Numerical Methods}

20. The coupled set of differential equations is solved numerically. The two first-order are solved using an adaptive step size, fourth-order Runge-Kutta method (Press et al. 1986). The partial differential equation is solved using the Crank-Nicolson technique (Chapra and Canale 1988).

21. The total number of years for which the model is run is determined by approximating the time required for the contaminant concentration in the 
water to decrease to 10 percent of the maximum value achieved. This is determined by using an analytical solution for the case where only the water and a single well-mixed layer are considered. This procedure has been found effective in approximating the total time. 
22. Use of the RECOVERY program is described in this section. Two files are required to run this program--RECOVERY.EXE and CORPCOMP.DAT. CORPCOMP.DAT contains the chemical database information. The other files included on the distribution disk are only required for specific hardware systems and to alter the database. (See Changing the Database and Specific System Issues below.) Source code for the model is also included (See Model Source). Do not run RECOVERY from a write-protected disk, as this will result in an error.

23. To start the program, move to the directory that contains the software and type a:RECOVERY at the DOS prompt. The first screen is a title screen. Press ENTER to view the introduction screen which follows. Press ENTER again and choose between creating a new file and retrieving data from an existing data file. If the second selection is made, any files ending in .REC and the subdirectories located in the current directory are displayed. The .REC files are the data files that are created when saving a run made by RECOVERY. (This will be discussed later). If your file is not located in the current directory or in one of the listed subdirectories, press BACKSPACE and specify the path name to your file. Your .REC file should then be displayed. After a file is chosen, you can either view and/or change the input file or just run the model using that data file. If "create a new file" is chosen, a list of compounds is displayed. The properties of 18 compounds are included in the database. If the compound under consideration is not listed, choose number 0 . The selection is made by moving the cursor to the desired selection using the arrow keys and pressing ENTER.

24. If selection 0 was made, a screen appears to enter the name of the contaminant. As the user types, the name will appear in the highlighted area. Corrections can be made by using the BACKSPACE or DELETE keys. After the name has been typed in, press ENTER to enter the name. If changes are necessary at this point, pressing F2 will allow modification of the name. If the user starts to type without pressing F2, the first entry is lost and the new name appears. This editing process is similar to that used by Lotus $1-2-3$ (R) and is used on all input screens. Press F10 to store the data and advance to the next screen.

25. The next five screens are used to enter or change input values. After typing in a cell, the user must press ENTER before proceeding to the 
next cell. The first morphometry and hydrology screen should be displayed. If a different compound is desired at this point, pressing ESCAPE will allow this change. The user may change or leave the water concentration at the default value of zero. Three of the next four values need to be entered. Press F9 to calculate the fourth and its values will be displayed. When all the data is entered, press F10 to store the values and advance to the next screen. If invalid values are entered, a message will appear at the bottom of the screen.

26. The next screen is for the contaminated sediments layer. If nothing is changed, the default values will be used. Press F10 to continue. System properties are listed on the next screen. Default values are listed for the first eight variables. These values can be changed as described above. Since the three velocity values are interrelated, two of the three values need to be entered. Typical values are listed in the center column. After entering two values, press F9 to calculate the third value. It will appear near the bottom of the screen. Press F10 to store the data and proceed.

27. The next two screens list contaminant properties. Default values are listed in the far right column and will be specific to the selected compound if it is in the database. These values will be used unless the user changed them in the center column. The second screen also contains intermediate values calculated from the previously entered data (e.g., Fdw, Kdw).

Press F10 to store and advance.

28. If the user wants to return to a previous screen in the input process described above, he/she can press ESCAPE until the desired screen appears.

29. The next screen serves as a check to see if the entered data are correct, and if not, the user can return to the input screens. Selecting the third option starts the model. If graphics capabilities are available on the system being used, the concentration profile in the deep sediments is displayed. The total number of years is calculated as the approximate time when the water concentration decreases to 10 percent of its maximum value. Since the numerical method uses an adaptive step size, the time between profile displays will not be even. When the computation is finished, a message appears in the lower right hand corner of the screen.

30. After a key is pressed, another menu appears. If one of the first five options is chosen or number 8 , this menu appears again so another 
selection can be made. Options $1-4$ are graphics plots. If the system being used does not have graphics capabilities, a message appears informing the user of this; a key can be pressed to return to the menu. Results on systems having graphics capabilities other than those listed in the program feature section of this report will be unpredictable. The first two plots are graphs of the contaminant concentration in the water layer and the mixed layer, respectively, versus time. The third plot shows the flux of the contaminant from the sediments to the water versus time. A graph of the volatilization rate of the contaminant will be displayed if number 4 is selected. These results can be printed by typing Shift+Print Screen. Select number 5 to print a table of results on the printer. Number 6 should be selected to make modifications to the existing run and number 7 should be used to return to the beginning of the program. Choose number 8 to save the existing run. The user will be prompted for a file name to be used to store the results. Choosing number 9 will result in exiting the program.

\section{Changing the Chemical Database}

31. Currently, data for 18 chemicals are included in the data file CORPCOMP.DATA. This file can be changed and enlarged to include a maximum of 39 compounds. Changes are made by altering the file CORPSDAT.BAS, which is included with the distribution disk. This file contains the following data for a compound:

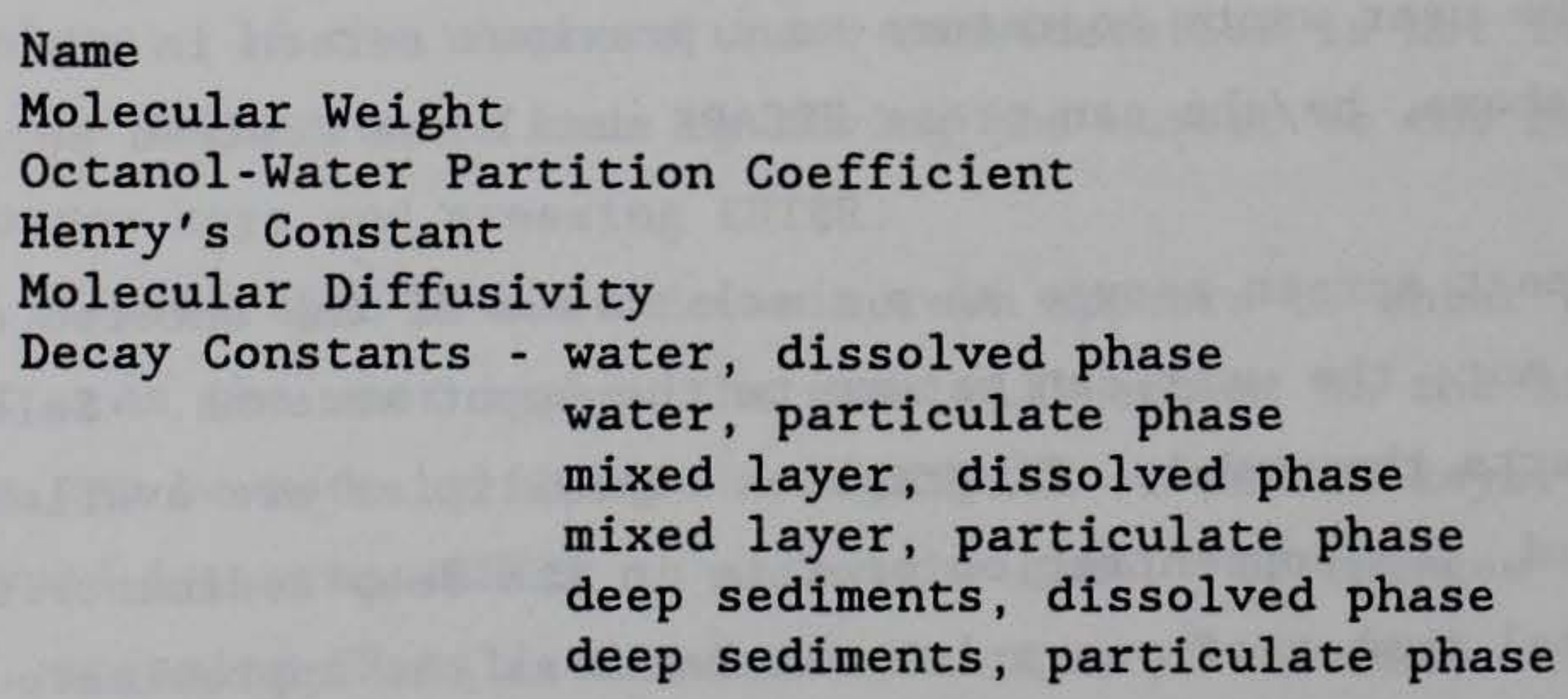

Additions and changes are made by altering or adding data statements to the file CORPSDAT.BAS and running the program. Errors will occur in RECOVERY when there are more than 39 compounds, a compound name with greater than 28 letters exists, or additional parameters are added to the data statements. 


\title{
Model Source
}

32. To access the model source code in the QuickBasic environment, type qb recovery $/ 1$ reclib when you are in a directory containing QuickBASIC Version 4.5 and the following files appear (included on the distribution disk).

\author{
RECOVERY.MAK \\ RECOVERY. BAS \\ CRANK. BAS \\ ADAPTEST. BAS \\ MODEL. BAS \\ RECLIB. QLB
}

\section{Program Features}

33. A list of data needed to run this program can be found in Table A2. Since the compound properties for several contaminants are included in the provided database, the user needs to provide compound properties only if the contaminant under consideration is not one that is in the database. The values in the database included on the distribution disk are listed in Table A3. The data file can be changed as described in the section "Changing the Chemical Database" on the previous page.

34. The data are entered on a series of input screens with editing capabilities. The user can easily page forward and backward through the screens while entering data. On-line help is also available. If any of the entered data are invalid, an error message appears instructing the user to reenter the data. For computers with graphic display capabilities, the deepsediment concentration profile will be displayed during the model computation.

35. The final results are displayed as plots on the screen and can be printed on a printer using the Shift+Print Screen command. Numerical results can be dumped to the printer also. The plots are:

a. Contaminant concentration in the water versus time.

b. Contaminant concentration in the mixed layer versus time.

c. Flux of the contaminant from the sediments into the water versus time.

d. Volatilization losses of the contaminant from the water versus time.

36. The input data can be stored on a disk and retrieved for later use. The user can also easily return to the input screens to make modifications. 
Table A2

Input Data for the Recovery Model

Water Column Morphometry/Hydrology: (3 specified, 4th computed)

Flow through, $\mathrm{m}^{3} /$ year

Residence time, year

Surface area, $\mathrm{m}^{2}$

Water depth, m

Water Layer:

Initial concentration, $\mu \mathrm{g} / \mathrm{m}^{3}$

Contaminated Sediments:

Depth of contaminated sediment layer, $m$

Depth of mixed Layer, $m$

Mixed layer surface area, $\mathrm{m}^{2}$

Initial concentrations, $\mu \mathrm{g} / \mathrm{m}^{3}$

Mixed layer

Deep contaminated sediments

System Properties:

Suspended solids concentration in water, $\mathrm{g} / \mathrm{m}^{3}$

Mixed layer porosity

Deep sediment porosity

Sediment particle density, $\mathrm{g} / \mathrm{m}^{3}$

Wind speed, $\mathrm{m} / \mathrm{sec}$

Fraction organic carbon, g-orgC/g-dry wt solids

Water layer

Mixed layer

Deep contaminated sediments

Two of the following three velocities:

Resuspension velocity, m/sec

Burial velocity, $\mathrm{m} / \mathrm{sec}$

Settling velocity, $\mathrm{m} / \mathrm{sec}$

Compound Properties:

Molecular diffusivity, $\mathrm{cm}^{2} / \mathrm{sec}$

Decay coefficients, year: particulate - water

dissolved - water

particulate - mixed layer

dissolved - mixed layer

particulate - deep sediments

Henry's constant, atm $-\mathrm{m}^{3} / \mathrm{gmole}$

dissolved - deep sediments

Octanol-water partition coefficient

Molecular weight, g/gmole 
Table A3

Compound Properties*

\begin{tabular}{|c|c|c|c|}
\hline Compound & $\begin{array}{c}\text { Henry's Constant } \\
\text { a } 25^{\circ} \mathrm{C} \\
\text { atm } \mathrm{m}^{3} / \mathrm{gmole} \\
\end{array}$ & $\log \left(K_{\text {ow }}\right)$ & $\begin{array}{l}\text { Molecular } \\
\text { Weight } \\
\text { g/gmole } \\
\end{array}$ \\
\hline Chlordane & $4.8 \times 10^{-5}$ & 2.78 & 409.6 \\
\hline DDT & $3.9 \times 10^{-5}$ & 5.00 & 354.5 \\
\hline Dieldrin & $2.0 \times 10^{-7}$ & 3.54 & 381.0 \\
\hline Lindane & $4.9 \times 10^{-7}$ & 3.70 & 290.0 \\
\hline Arochlor 1242 & $8.4 \times 10^{-3}$ & 6.72 & 328.4 \\
\hline Arochlor 1248 & $3.5 \times 10^{-3}$ & 6.00 & 295.0 \\
\hline Arochlor 1254 & $2.8 \times 10^{-3}$ & 6.00 & 326.0 \\
\hline Arochlor 1260 & $7.1 \times 10^{-3}$ & 6.50 & 361.0 \\
\hline Benzene & $5.5 \times 10^{-3}$ & 2.10 & 78.0 \\
\hline Chlorobenzene & $3.7 \times 10^{-3}$ & 2.98 & 112.6 \\
\hline Ethylbenzene & $8.7 \times 10^{-3}$ & 3.15 & 106.0 \\
\hline Pentachlorophenol & $3.4 \times 10^{-6}$ & 5.00 & 266.0 \\
\hline Phenol & 1. $3 \times 10^{-6}$ & 1.46 & 94.1 \\
\hline Toluene & $6.7 \times 10^{-3}$ & 2.70 & 92.0 \\
\hline Anthracene & $1.7 \times 10^{-3}$ & 4.45 & 178.2 \\
\hline Benzo (a)pyrene & $7.2 \times 10^{-7}$ & 5.00 & 252.0 \\
\hline Naphthalene & $4.3 \times 10^{-4}$ & 3.36 & 128.0 \\
\hline Chloroform & $4.2 \times 10^{-3}$ & 1.95 & 119.0 \\
\hline Fluoranthene & $1.6 \times 10^{-2}$ & 5.33 & 202.3 \\
\hline
\end{tabular}

* Values for Henry's constant, $\mathrm{K}_{\mathrm{ow}}$, and molecular weight are from Lyman et al. (1982), Schnoor et al. (1987), and Thomann and Mueller (1987). The default values for all molecular diffusivities are $5 \times 10^{-6} \mathrm{~cm}^{2} / \mathrm{s}$. The default values for all decay coefficients are zero.

37. This program is written in Microsoft QuickBASIC 4.5 and has been written for the following combinations of graphic adapters and displays:

CGA and Color Display

EGA and Monochrome Display

EGA and Color Display

EGA and Enhanced Color Display

VGA and Monochrome Display

VGA and Color Display

Hercules Video Card and Monochrome Display

38. A math coprocessor is not required to run RECOVERY. The use of a coprocessor, however, will decrease the computation time. 


\section{System Specific Issues}

39. Some procedures that are specific to particular hardware systems are described below. If you have problems running RECOVERY, please consult these.

\section{Use of Hercules Graphics Card}

40. If your system has a Hercules Graphics Card, you will need to load the Hercules driver before running the program. The driver, MSHERC.COM, ((C) Copyright Microsoft Corporation, 1987, 1988) is provided on the distribution disk. To run the program, type MSHERC. If you do not run this program, the model should run but not display any graphics.

Strange sediment profile results

41. If your system has all of the following characteristics, you may have floating-point math problems.

a. Uses MS-DOS Version 3.20.

b. Boots from a hard drive.

c. Has a math coprocessor (for instance, an 8087 chip).

These problems can be avoided by booting the computer from a floppy disk drive instead of the hard drive.

WARNING: If you have floating-point math problems, the model information will not be correct. This should be evident by the graphical results. Use of a Compaq 386 with a math coprocessor

42. If you are using a Compaq 386 that has a math coprocessor installed, RECOVERY may crash. To use the model, turn the coprocessor off by adding the line, SET NO87 $=$ ' ', to the CONFIG.SYS file and rebooting your machine. 


\section{Installation}

43. Two BAT files are included in the RECOVERY diskette to aid in the installation and execution of RECOVERY. The RECOVERY program can be installed in the hard disk of your computer by following the steps outlined below:

a. Turn your computer on.

b. Insert the RECOVERY diskettes into drive A: or B:.

c. At the DOS prompt ( $>$ or $C:>$ ), type $A$ : and press ENTER.

d. At the $A:>$ prompt, type INSTALL. Press ENTER.

e. The BAT file INSTALL will start the installation.

Note: Answer all questions and make the requested changes.

\section{$\underline{\text { RUN }}$}

44. To run the RECOVERY program follow these steps:

a. At the DOS prompt (> or C:>), type RECOVERY (or recovery).

b. At the Dos prompt ( $>$ or $C:>$ ), type RECOVERY $R$ and view with GRAPHER the water concentration and mixed sediment concentration.

NOTE: Make sure the modifications that were explained in the INSTALL are done and the RECOVERY.BAT is in a directory that must be included in the path statement.

\section{Notes on RECOVERY.BAT}

45. This file runs the RECOVERY program from anywhere in your hard disk. However, if this program is installed in a drive other than " $C$ :, " it must be modified. If the program is installed in drive " $D:$, " edit the RECOVERY.BAT file by changing "c:" to "d:" where indicated. The changes will be indicated by "rem" before and after the statements that need modification.

46. The graphics package GRAPHER is not included with RECOVERY. If an auxiliary graphics is needed, GRAPHER is a suggested software package. However there are other graphics packages that will perform similar tasks. The use of GRAPHER does not constitute an endorsement of the product. 
$\begin{array}{ll}\text { README } & \text { 1ST } \\ \text { ANSWER } & \text { COM } \\ \text { INSTAL } & \text { BAT }\end{array}$

RECOVERY BAT

RECOVERY <DIR $>$

COMPLINK BAT

RECOMLIN BAT

MSHERC COM

RECLIB LIB

RECLIB QLB

RECOVERY MAK

RECOVERY EXE

CORPCOMP DAT

CORPSDAT BAS

CRANK BAS

MODEL BAS

RECOVERY BAS

ADAPTEST BAS

RESUL DAT

ANTH REC

CHLOR REC

PCB REC

DDE REC

DIELDRIN REC

LINDANE REC

GRAPHS $\quad\langle$ DIR $>$

RESUL DAT

SEDDATA GRF

SEDDATA PLT

WATDATA GRF

WATDATA PLT

TITLESED TXT

TITLEWAT TXT

$X$-ALLDAT AXS

Y-SEDIM AXS
This file.

A utility that allows interactive bat files.

Interactive installation program. Allows the user to install RECOVERY in a selected hard disk drive from the floppy drive A:

The bat file is used to run RECOVERY with or without using the GRAPHER software.

Location of all RECOVERY files.

Directory of A: \RECOVERY.

\section{Utilities}

Bat files for compiling and linking RECOVERY using QUICK BASIC 4.5.

Utility for computers with a Hercules Graphics Monitor; use is described in the enclosed manual.

Libraries for recompiling RECOVERY using Microsoft Quick Basic 4.5 including the graphics subroutines and other proprietary software.

The executable file.

Program data set to modify, add, or delete the RECOVERY database. Run under Quick Basic 4.5.

The RECOVERY model RECOVERY.BAS calls the Graphic subroutines and runs the model (MODEL.BAS).

CRANK.BAS and ADAPTEST.BAS are the numerical subroutines to solve the sediment model (layers) or the water and mixed sediment compartments.

File with the results of the last run.

Data files of different RECOVERY runs enclosed as examples for future runs.

Location of files that interact with GRAPHER.

Directory of $A: \backslash$ RECOVERY $\backslash$ GRAPHS

File with the results of the last run.

Files created for viewing the results using the software GRAPHER. 


\section{Y-SEDIM2 AXS}

Y-WATER AXS 


\section{RECOVERY}

A Decision Support Model for Screening the Fate of In-Place Contaminated Sediments in Aquatic Environments

June, 1989

Beta Test Version 1.0

Written for The U.S. Army Corps of Engineers Waterways Experiment Station and

New England Division

Written by Jean M. Boyer and Steven C. Chapra Center for Advanced Decision Suppport

in Water and Environmental Sytems University of Colorado Boulder, CO 80309-0428

MsHerc program (C) Copyright ' 87 , '88 Microsoft Corp. All Rights reserved.

Press any key to continue.

\section{SCREEN 1}

This program is a tool for screening the fate of in-place contaminated sediments in aquatic environments. It predicts the concentration of a contaminant in the water, the mixed sediment layer and in the deep sediments over time. The flux of the contaminant from the sediments into the water is also predicted. Note that the total number of years for which the model is run is determined by approximating the time required for the toxic concentration in the water to decrease to $10 \%$ of the maximum value achieved, up to a maximum of 100 years.

Please refer to the documentation accompanying this software for detailed instructions and model theory.

If you need help while entering data into an input screen, press $F 1$. Press $\mathrm{Ctrl}+\mathrm{Break}$ to terminate the program at any time. Press Shift+Print Screen to print a graph displayed on the screen.

Press any key to continue.

SCREEN 2 
Highlight your choice and press Enter or press the number preceding your selection.

1. Create a new file.

2. Retrieve data from an existing file.

\section{SCREEN 3}

These are the .REC files and subdirectories listed in the specified directory. Highlight one of these using the up and down arrows and press Enter or press Backspace to specify an alternative directory. Press escape to return to the previous screen.

Directory: C:IQB45I

CHLOR.REC ANTH.REC

SCREEN $4 a$ 
The properties of the following contaminants are included in the database. If the contaminant you want to consider is not listed, choose 0 .

Highlight your choice using the arrow keys and press ENTER.
0. Compound Not Listed
1. Chlordane
2. DDT
3. Dieldrin
4. Lindane
5. Arochlor 1242
6. Arochlor 1248
7. Arochlor 1254
8. Arochlor 1260
9. Benzene

10. Chlorobenzene

11. Ethyl Benzene

12. Pentachlorophenol

13. Phenol

14. Toluene

15. Anthracene

16. Benzo(a)pyrene

17. Naphthalene

18. Chloroform

\section{SCREEN 4b}

Highlight your choice and press Enter or press the number preceding your selection.

1. View/Change Input file.

2. Run Using Input File.

\section{SCREEN 5}




\section{MORPHOMETRY AND HYDROLOGY}

\section{Water}

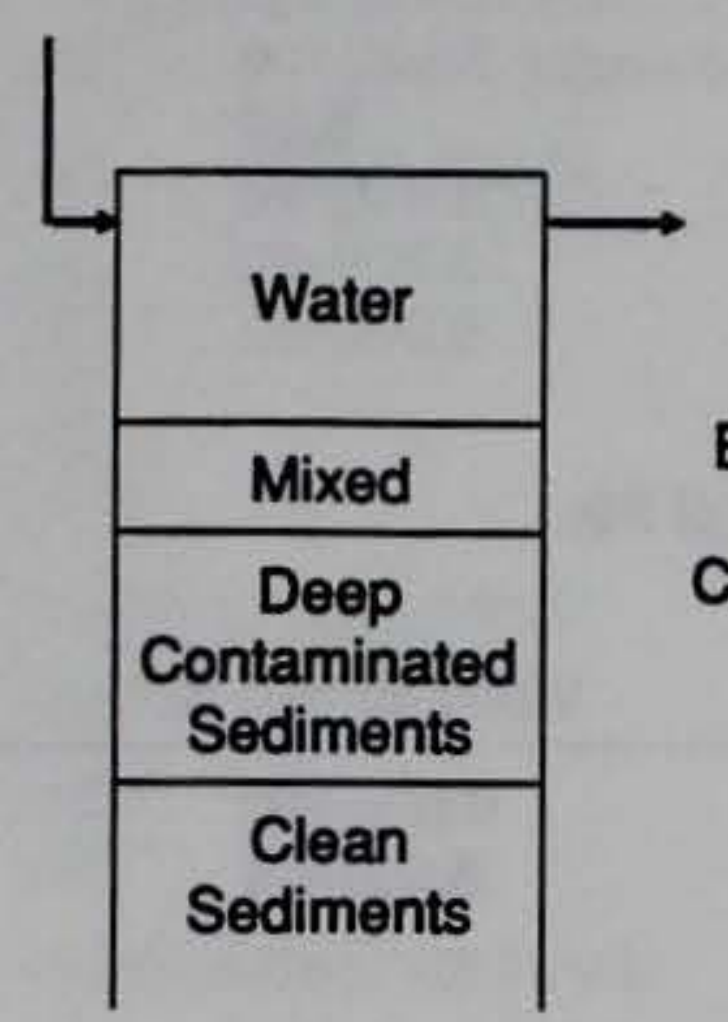

Initial Concentration of

Chlordane $\left(\mu \mathrm{g} / \mathrm{m}^{\wedge} 3\right)$ :

$0.000 \mathrm{E}+00$

NTER 3 OF THE FOLLOWING 4 VALUES AND PRESS F9:

Calculated Residence Time (years): $\quad \mathbf{5 . 0 0}$

Help-F1 Edit-F2 ReCalc-F9 Store Data/Advance-F10 Change Compound-Esc

\section{SCREEN 6}

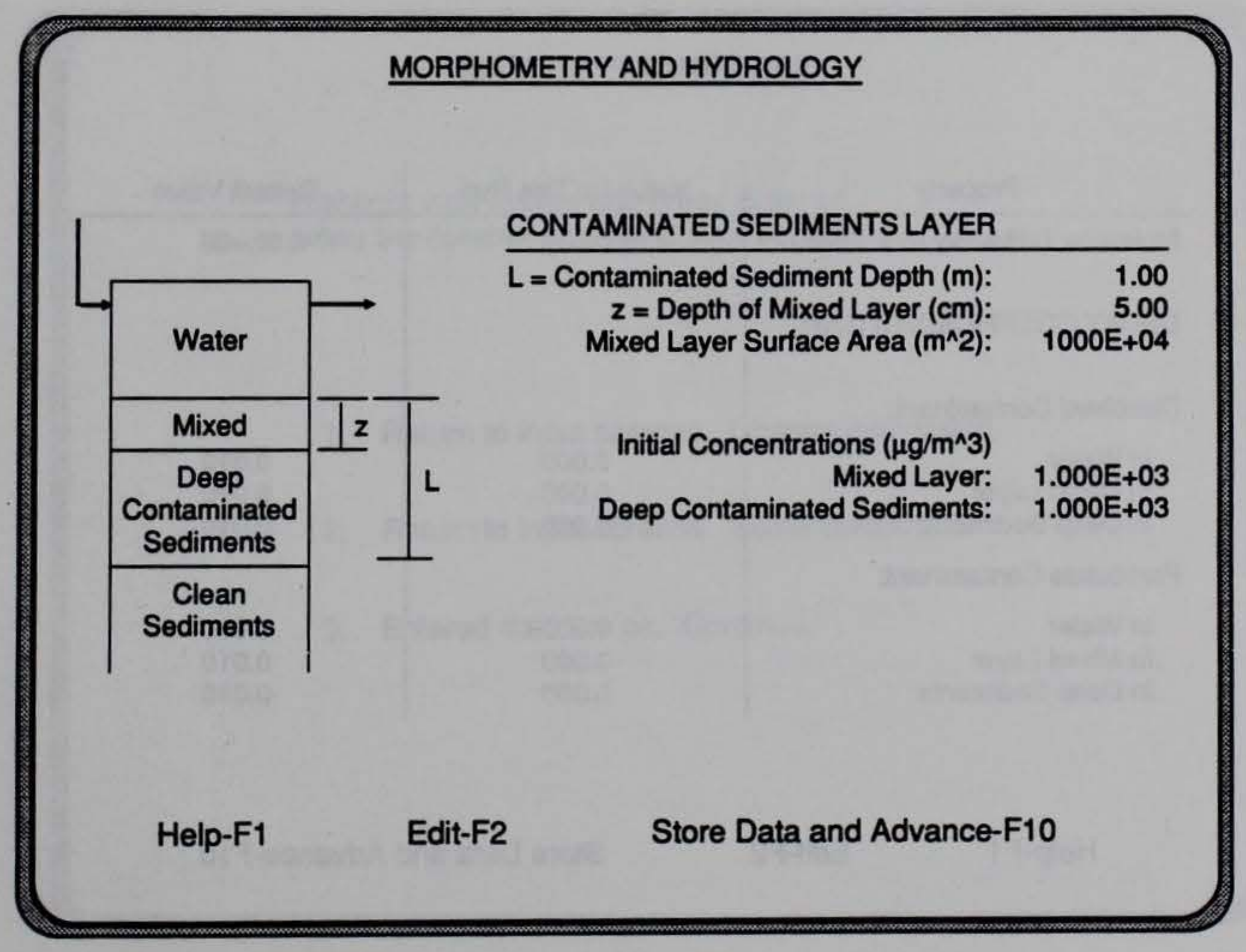

SCREEN 7 


\section{SYSTEM PROPERTIES}

Suspended Solids Concentration in Water $\left(g / \mathrm{m}^{\wedge} 3\right)$ :

Mixed Sediment Porosity:

Deep Sediment Porosity:

Mixed Sediment Particle Density $\left(g / \mathrm{m}^{\wedge} 3\right)$ :

Deep Sediment Particle Density $\left(g / \mathrm{m}^{\wedge} 3\right)$ :

Wind Speed (m/sec):

Weight fraction carbon in solid - water:

Weight fraction carbon in solid - mixed layer:

Weight fraction carbon in solid - sediments:

INPUT TWO OF THE FOLLOWING VELOCITIES AND PRESS F9:

\begin{tabular}{l|c|c}
\multicolumn{1}{c|}{ Velocity (m/yr) } & Typical Value & Value for this Run \\
\hline Resuspension Velocity: & $0.00 E+00$ & $0.00 E+00$ \\
Burial Velocity: & $5.34 E-04$ & $5.00 E-04$ \\
Settling Velocity: & $1.00 E+02$ &
\end{tabular}

Calculated Settling Velocity $(\mathrm{m} / \mathrm{yr})$ :

9.37E+01

Help-F1 Edit-F2 ReCalc-F9 Store Data and Advance-F10

\section{SCREEN 8}

\begin{tabular}{|c|c|c|}
\hline \multirow[b]{2}{*}{ Property } & DANE PROPERTIES & \multirow[b]{2}{*}{ Default Value } \\
\hline & Value for This Run & \\
\hline Molecular Diffusivity (cm^2/sec) & $5.0 \mathrm{E}-06$ & $5.0 \mathrm{E}=06$ \\
\hline \multicolumn{3}{|l|}{ DECAY COEFFICIENTS (1/yr) } \\
\hline \multicolumn{3}{|l|}{ Dissolved Contaminant: } \\
\hline $\begin{array}{l}\text { In Water } \\
\text { In Mixed Layer } \\
\text { In Deep Sediments }\end{array}$ & $\begin{array}{l}0.000 \\
0.000 \\
0.000\end{array}$ & $\begin{array}{l}0.010 \\
0.010 \\
0.010\end{array}$ \\
\hline \multicolumn{3}{|l|}{ Particulate Contaminant: } \\
\hline $\begin{array}{l}\text { In Water } \\
\text { In Mixed Layer } \\
\text { In Deep Sediments }\end{array}$ & $\begin{array}{l}0.000 \\
0.000 \\
0.000\end{array}$ & $\begin{array}{l}0.010 \\
0.010 \\
0.010\end{array}$ \\
\hline Help-F1 & Store Data & rance-F10 \\
\hline
\end{tabular}

SCREEN 9 
CHLORDANE PROPERTIES

\begin{tabular}{l|c|c}
\multicolumn{1}{c|}{ Property } & Value for This Run & Default Value \\
\hline $\begin{array}{l}\text { Henry's Con. (atm-m^3/gmole) } \\
\text { Molecular Weight }\end{array}$ & $4.80 \mathrm{E}-05$ & $4.80 \mathrm{E}-05$ \\
Octanol-Water Partition Coeff. & 409.60 & 409.60 \\
(mg/m^3 octanol)/(mg/m^3 water) & $6.03 \mathrm{E}+02$ & $6.03 \mathrm{E}+02$ \\
CALCULATED DATA & & \\
Fdw & & \\
Fpw & $1.00 \mathrm{E}+00$ & $1.00 \mathrm{E}+00$ \\
Fdpm & $3.72 \mathrm{E}-05$ & $3.72 \mathrm{E}-05$ \\
Fdps & $1.28 \mathrm{E}-01$ & $1.28 \mathrm{E}-01$ \\
Partition Coefficients & $1.28 \mathrm{E}-01$ & $1.28 \mathrm{E}-01$ \\
Kdw & & \\
Kdm & & $1.86 \mathrm{E}-05$ \\
Kds & $1.86 \mathrm{E}-05$ & $1.86 \mathrm{E}-0.5$ \\
Volatilization rate (1/yr) & $1.86 \mathrm{E}-0.5$ & $1.86 \mathrm{E}-0.5$ \\
& $1.86 \mathrm{E}-0.5$ & $1.14 \mathrm{E}+01$
\end{tabular}

Help-F1 Edit-F2 ReCalc-F9 Store Data and Advance-F10

SCREEN 10

Highlight your choice and press Enter or press the number preceding your selection.

1. Return to input screens. Change compound.

2. Return to input screens. Same compound.

3. Entered data are ok. Continue.

SCREEN 11 
Concentration Profile Below the Mixed Sediment Layer (depth in $\mathrm{m}$ ) Chlordane

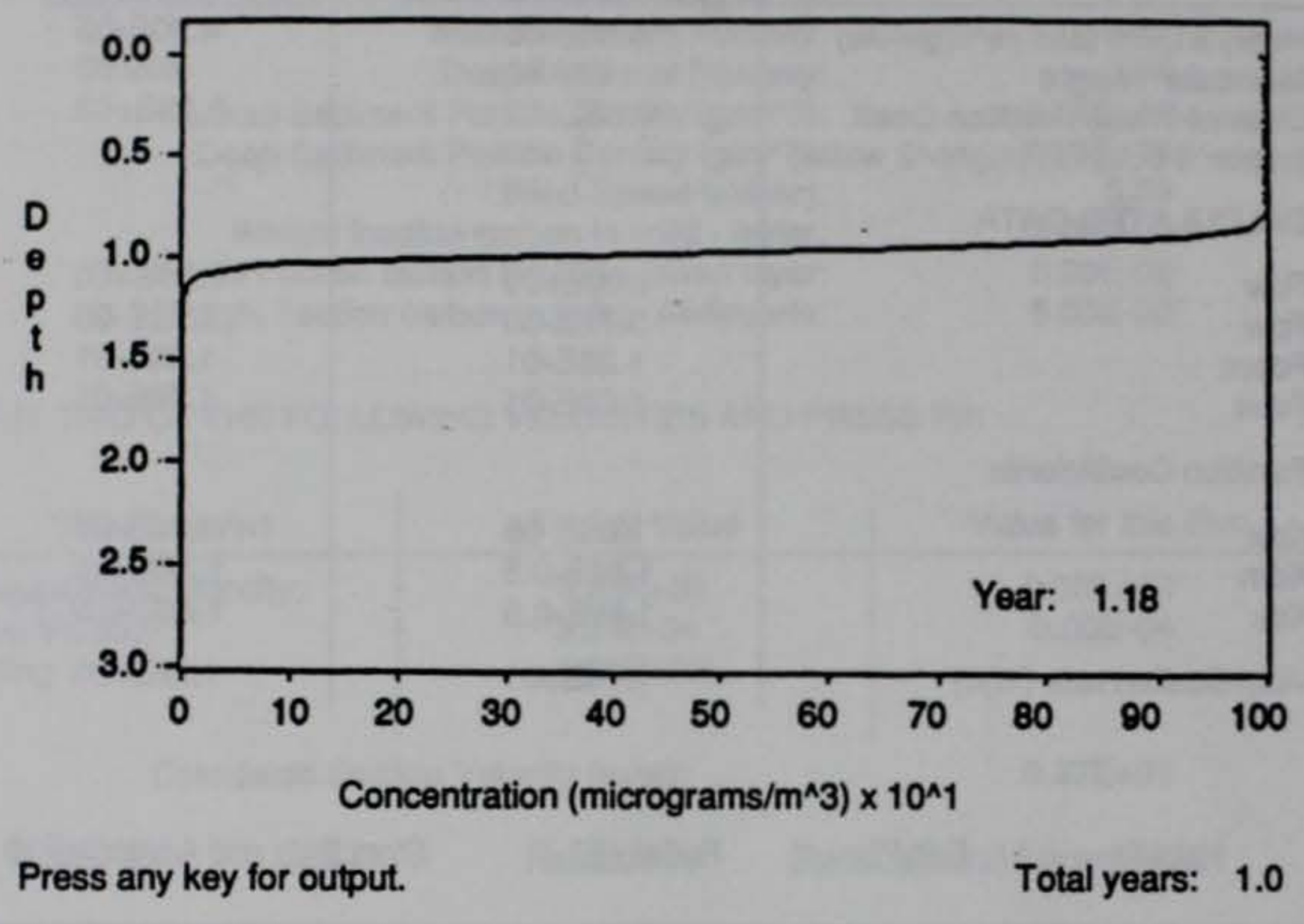

\section{SCREEN 12}

Highlight your choice and press Enter or press the number preceding your selection.

1. Plot Contaminant Concentration in Water.

2. Plot Contaminant Concentration in Mixed Layer.

3. Plot Flux of Contaminant from Sediments into Water.

4. Plot Volatilization Rate from the Water.

5. Print Table of Results to Printer.

6. Return to Input Screens.

7. Return to Beginning of Program.

8. Save the Input Data for This Run.

9. Exit Program.

\section{SCREEN 13}


Chlordane Concentration in the Water (micrograms $/ m^{\wedge} 3$ )

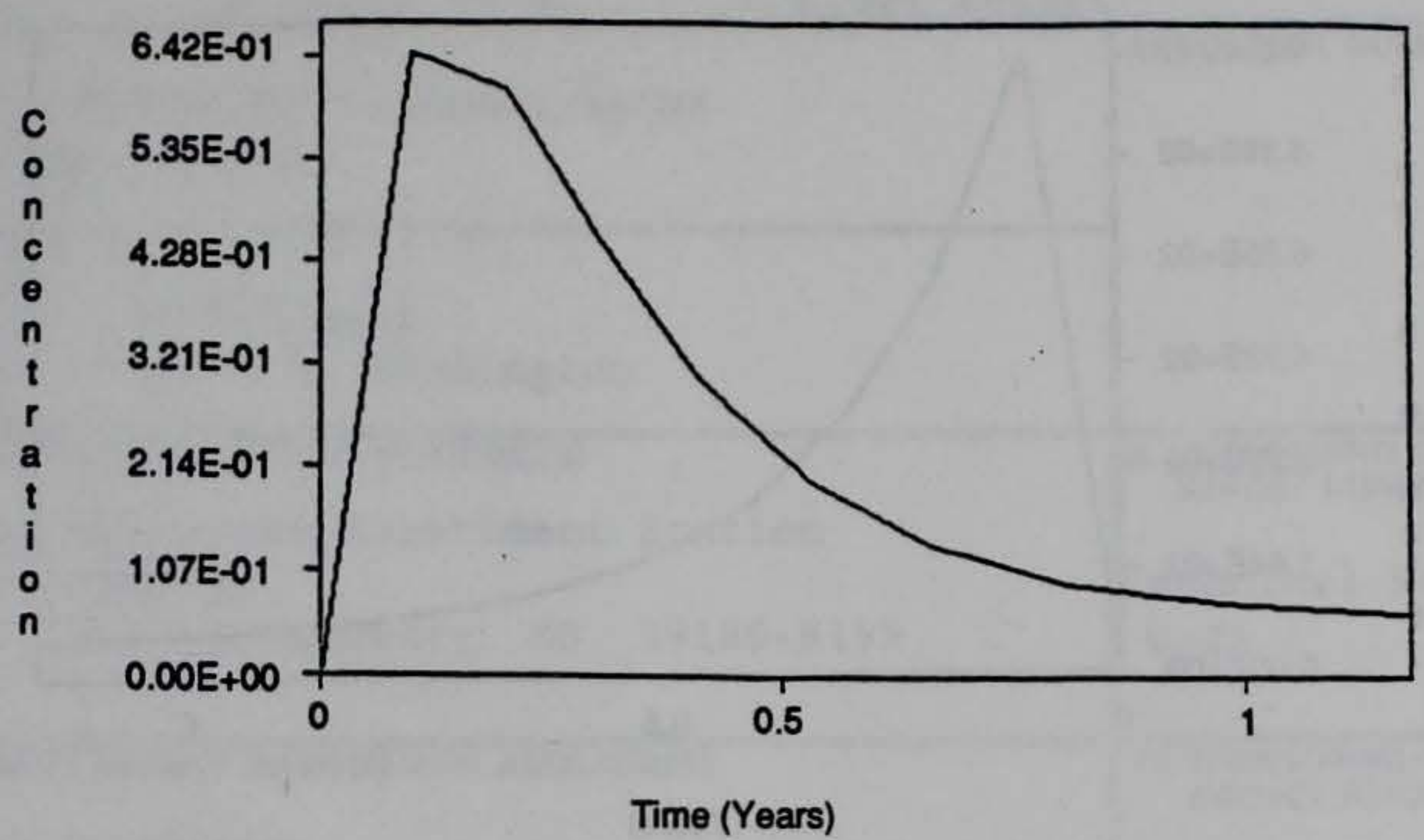

Press Shift+PrintScreen to print.

Press any key to continue.

\section{SCREEN 14}

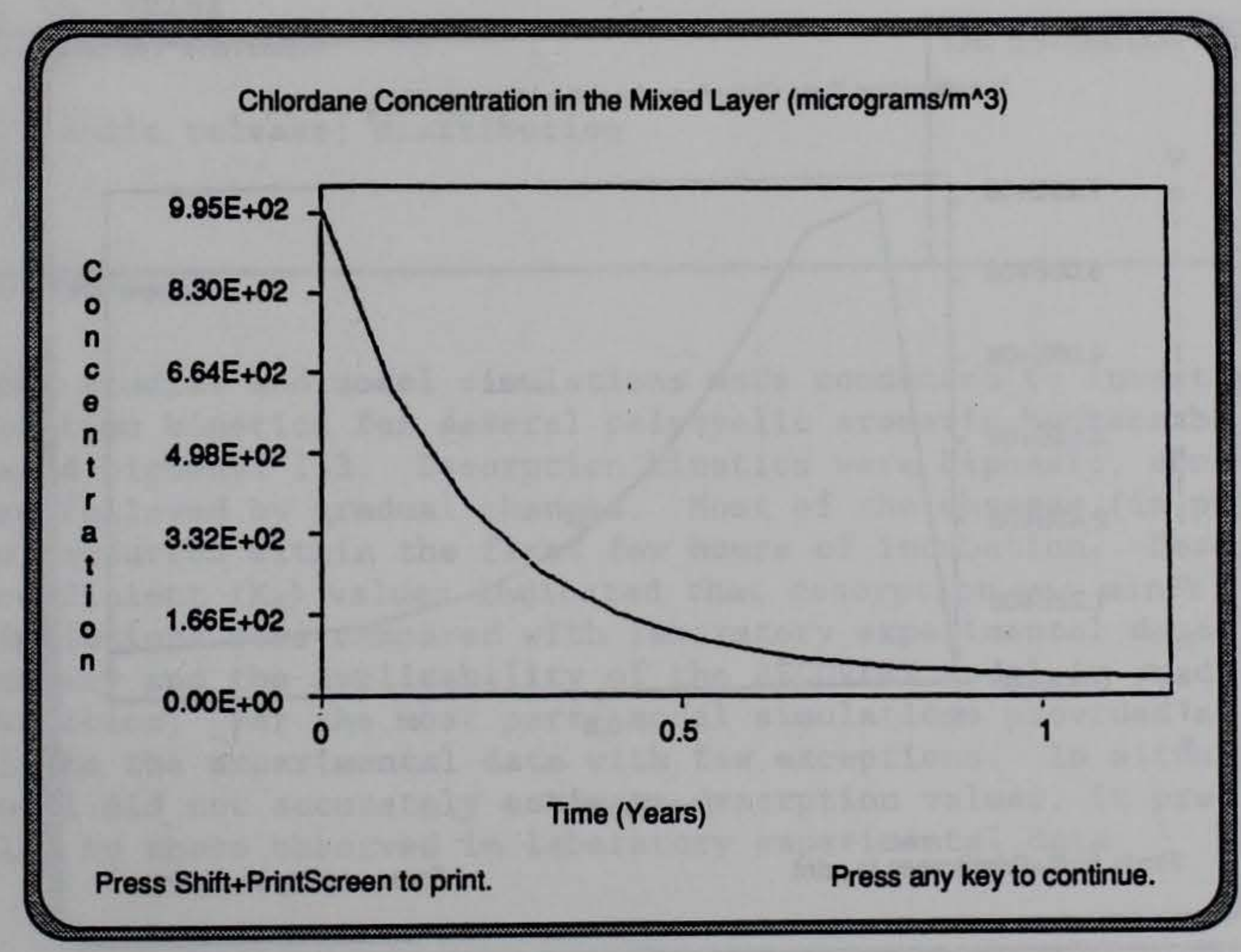

SCREEN 15 
Flux of Chlordane into Water from Sediments (micrograms/(m^2-yr))

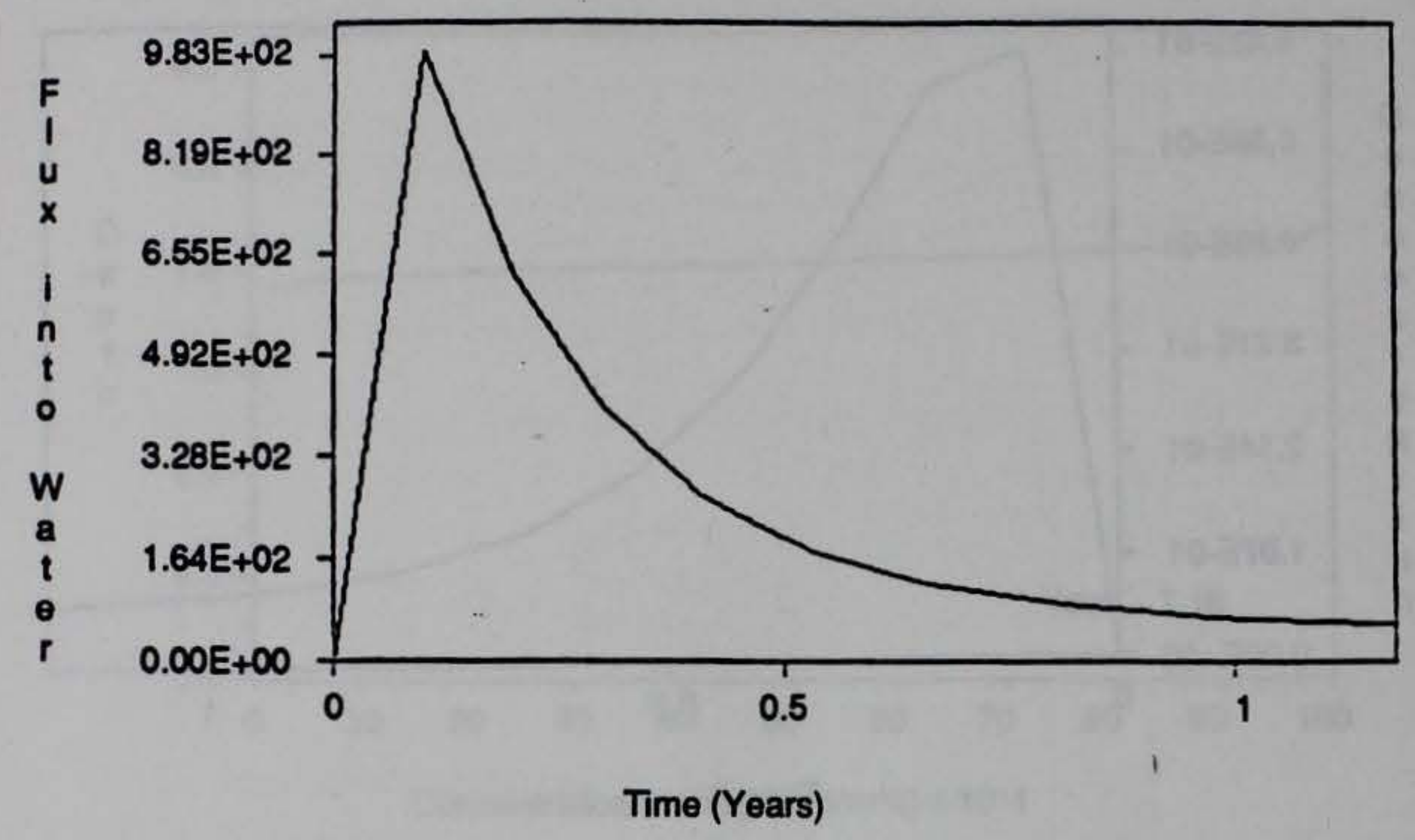

Press Shift+PrintScreen to print.

Press any key to continue.

\section{SCREEN 16}

Volatilization Rate Chlordane from the Water (micrograms/yr)

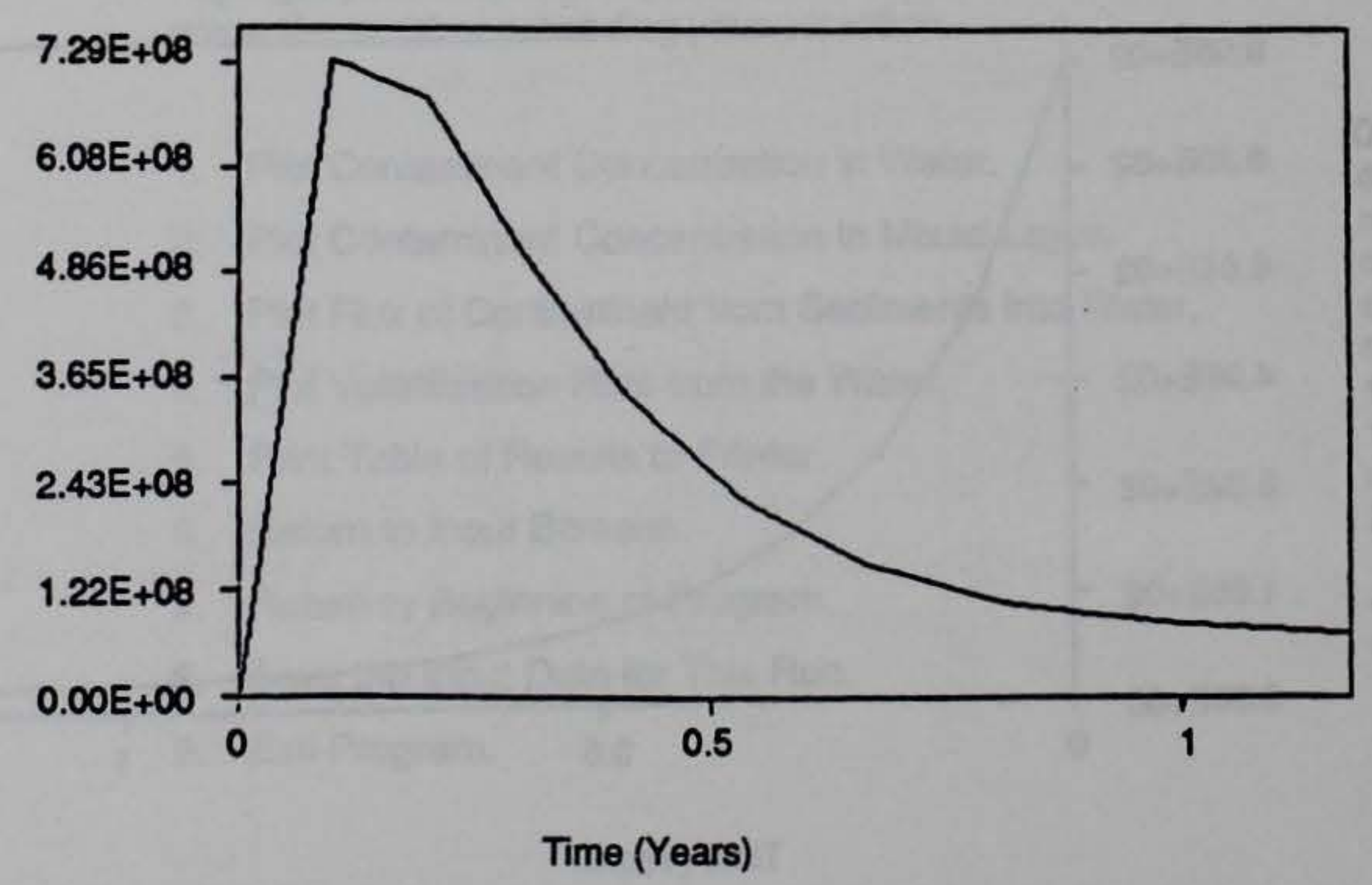

Press Shift+PrintScreen to print.

Press any key to continue.

SCREEN 17 
Public reporting burden for this collection of information is estimated to average 1 hour per response, including the time for reviewing instructions, searching existing data sources. gathering and maintaining the data needed, and completing and reviewing the collection of information. Send comments regarding this burden estimate or any other aspect of this

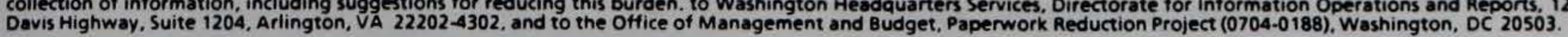

\begin{tabular}{|l|l|l|} 
1. AGENCY USE ONLY (Leave blank) & 2. REPORT DATE & 3. REPORT TYPE AND DATES COVERED
\end{tabular}

\section{TITLE AND SUBTITLE} April 1993 Final report

Description of Contaminant Sediment-Water Interactions Using RECOVERY

6. AUTHOR(S)

Thomas C. Sturgis, Carlos Ruiz, Douglas Gunnison, Judith C. Pennington

\section{PERFORMING ORGANIZATION NAME(S) AND ADDRESS(ES)}

US Army Engineer Waterways Experiment Station Environmental Laboratory 3909 Halls Ferry Road, Vicksburg, MS 39180-6199

\section{FUNDING NUMBERS}

\section{SPONSORING/MONITORING AGENCY NAME(S) AND ADDRESS(ES)}

US Army Corps of Engineers

Washington, DC 20314-1000

8. PERFORMING ORGANIZATION REPORT NUMBER

Technical Report W-93-1

\section{SUPPLEMENTARY NOTES}

Available from National Technical Information Service, 5285 Port Royal Road, Springfield, VA 22161

Approved for public release; distribution is unlimited

\section{ABSTRACT (Maximum 200 words)}

Laboratory studies and model simulations were conducted to investigate and predict desorption kinetics for several polycyclic aromatic hydrocarbons and polychlorinated biphenyl 153. Desorption kinetics were biphasic, consisting of a rapid phase followed by gradual changes. Most of the changes (in percent of steady-state) occurred within the first few hours of incubation. Desorption partition coefficient $\left(\mathrm{K}_{\mathrm{d}}\right)$ values indicated that desorption was minor.

Model simulations were compared with laboratory experimental data to evaluate the accuracy and the applicability of the RECOVERY model in predicting desorption kinetics. For the most part, model simulations provided a reasonably good fit to the experimental data with few exceptions. In situations where the model did not accurately estimate desorption values, it predicted trends similar to those observed in laboratory experimental data.

\section{SUBJECT TERMS}

See reverse.

18. SECURITY CLASSIFICATION OF THIS PAGE

19. UNCLASSIFIED 
14. (Concluded).

Desorption

Distribution coefficient Polychlorinated biphenyl

Fluoranthene

Naphthalene
RECOVERY

Sediment-water 